SPAL 30.2 $(2021)$

\section{8-339}

ISSN: $1133-4525$

ISSN-e: 2255-3924

FECHA RECEPCIÓN

05/09/2020

FECHA ACEPTACIÓN

$15 / 12 / 2020$

\title{
Arqueología de los condados castellanos. Sociedades locales y prácticas políticas en Lantarón (siglos IX-X)
}

\author{
ARCHAEOLOGY OF THE CASTILE COUNTIES. LOCAL SOCIETIES AND POLITICAL PRACTICES \\ IN LANTARON (9TH-10TH CENTURIES)
}

\author{
Juan Antonio Quirós Castillo \\ Universidad del País Vasco / Euskal Herriko Unibertsitatea \\ Depto Geografía, Prehistoria y Arqueología \\ C/ F. Tomás y Valiente s/n. 01006 Vitoria-Gasteiz \\ quiros.castillo@ehu.eus (1) 0000-0002-4676-102X P F-1724-2016
}

Resumen El objetivo de este artículo es analizar los condados castellanos altomedievales a partir del estudio de las prácticas sociopolíticas y las formas de territorialización del poder. La emergencia en los últimos decenios de una historia social del poder en el noroeste peninsular ha permitido proponer algunos itinerarios interpretativos que inciden, principalmente, en la agencia de los personajes connotados con el título condal. No obstante, el incremento de las intervenciones arqueológicas disponibles permite identificar algunos rasgos de las sociedades locales y analizar, desde nuevas perspectivas, las dinámicas sociales y políticas del área castellana. Este trabajo se centra en el caso de Lantarón, uno de los territorios de menores dimensiones a cuya cabeza aparece un conde en los siglos IX-X. Recurriendo a un análisis multiescalar y comparativo se argumenta que la fuerte identidad de las sociedades locales, la existencia de un alto grado de compartimentación política y la dispersión funcional de los centros de autoridad permitió la construcción de formas de territorialización relacional. Esta nueva territorialización permitió que se ensanchasen los horizontes de las prácticas políticas a distintas escalas. El caso de estudio de Lantarón permite proponer un tipo ideal de estado relacional en el que los consensos y las redes políticas son más relevantes que las bases patrimoniales del poder.

Palabras clave Estado, Poder, Autoridad, Legitimidad, Heterarquía jerárquica, Territorialización relacional, Patronazgo

Abstract This paper aims to study sociopolitical practices and the territorial shapes of power in the early medieval Castilian counties. The emergence in recent decades of a robust social history of power in north-western Iberia has allowed to propose new interpretive frameworks stressing the role of aristocracy and county elite. However, the new archaeological records are challenging these assumptions providing some features of local societies and analyzing, from new perspectives, the social and political dynamics of the Castilian area. This work is focused on the case of Lantarón, one of the smaller territories at the head of which an count is attested in the 9th-10th centuries. Using a multi-scale and comparative analysis, it is argued that the strong identity of local societies, the existence of a high degree of political compartmentalization and the dispersion of different centers of authority allowed the construction of forms of a relational territorialization. This new territorialization has opened the horizons of political practices at different scales. Lantarón's case study allows us to propose an ideal type of relational state in which consensus and political networks are more relevant than the patrimonial bases of power.

Keywords State, Power, Authority, Hierarchical heterarchy, Relational Territorialization, Patronage

Quirós Castillo, J.A. (2021): "Arqueología de los condados castellanos. Sociedades locales y prácticas políticas en Lantarón (siglos IX-X)", Spal, 30.2, pp. 308-339. https://dx.doi.org/10.12795/spal.2021.i30.26 
SPAL 30.2

(2021)

\section{8-339}

ISSN: 1133-4525 ISSN-e: 2255-3924

\section{INTRODUCCIÓN}

Una de las principales consecuencias de la crisis del 2007-2008 ha sido mostrar la debilidad y las limitaciones del tejido institucional sobre los que se basa el modelo del "estado del bienestar" en Occidente. La emergencia de distintas formas de nacionalpopulismos, o de movimientos como los gilets jaunes no son sino una muestra de las tensiones creadas por unas expectativas no cumplidas por parte de los aparentemente garantistas estados-nación o por la misma Unión Europea. Y la crisis post-covid está incidiendo ulteriormente en esta línea. En este contexto las Ciencias Sociales han prestado una atención creciente a la teoría y la naturaleza del estado. Como consecuencia de ello, disciplinas como la Antropología Social, la Historia Económica o la Sociología han desarrollado nuevos enfoques acerca de la creación y el funcionamiento de los estados, la complejidad social o el incremento de la desigualdad económica (p.e. Jessop, 2016; Milanovic, 2016; Scheidel, 2017). También la Arqueología está desarrollando un importante corpus de estudios sobre el estado y la complejidad social, reemplazando los modelos unilineales del evolucionismo social procesual por explicaciones más complejas, evitando argumentos teleológicos y adoptando perspectivas multilineales y multiestratificadas (p.e. Flannery y Marcus, 2012; Marcus, 2008; Price y Feinman, 2012; Terrenato y Haggis, 2011).

Las formaciones estatales que se desarrollaron en Europa tras el colapso del Imperio Romano constituyen un escenario privilegiado para el estudio de prácticas políticas a varias escalas, puesto que fueron verdaderos laboratorios de experimentación y de construcción de comunidades políticas de distinta entidad. De hecho, el estudio de la formación de los estados postromanos es una de las principales temáticas de estudio de la Arqueología Medieval en el Reino Unido (Reynolds, 2018) o en Escandinavia ( $\varnothing$ degaard, 2013). En cambio, en el sur de Europa la huella del estado antiguo y la persistencia de formas de estatalidad romana ha determinado que, salvo excepciones puntuales (como por ejemplo la formación del estado islámico declinado en términos de islamización social, Gutiérrez Lloret, 2017), los arqueólogos no hayan sido tan explícitos a la hora de estudiar los procesos de construcción, colapso y articulación de los estados postromanos. Sin embargo, esta tendencia está cambiando en los últimos años, ya que se están realizando importantes aportaciones, tanto desde las fuentes materiales como de las documentales (p.e. Bianchi et al., 2018; Díaz Martínez y Martín Viso, 2011; Escalona Monge et al., 2019; Loré y Bougard, 2019; Pohl y Wieser, 2009).

El ejemplo del Noroeste de la Península Ibérica reviste un particular interés en este debate sobre las morfologías políticas postromanas. En el medio milenio comprendido entre el colapso del Imperio Romano y el año mil se han sucedido una amplia diversidad de poderes que incluyen el estado suevo, el visigodo, el astur-leonés, el de Pamplona, los condados castellanos o un efímero dominio andalusí. Como consecuencia de ello, en el último decenio se ha desarrollado una verdadera historia social del poder que ha llevado a redefinir, desde nuevas perspectivas, las prácticas políticas en algunos de estos reinos (Carvajal Castro, 2017; Castellanos y Martín Viso, 2005; Fernández, 2017; Martín Viso, 2019). Algunos de los principales itinerarios temáticos analizados han sido el estudio del papel de la guerra (Larrea Conde, 2009), los territorios sin estado (Martín Viso, 2017), el uso de nociones como escala y cambio de escala (Escalona Monge y Reynolds, 2011), los procesos de colapso estatal y resiliencia de los poderes locales (Martín Viso, 2016), las prácticas judiciales (Davies, 2016) o las formas de integración, negociación y competición entre poderes locales y centrales (Santos Salazar, 2019). Pero en rigor aún carecemos 
SPAL 30.2

(2021)

\section{8-339}

ISSN: $1133-4525$ ISSN-e: 2255-3924

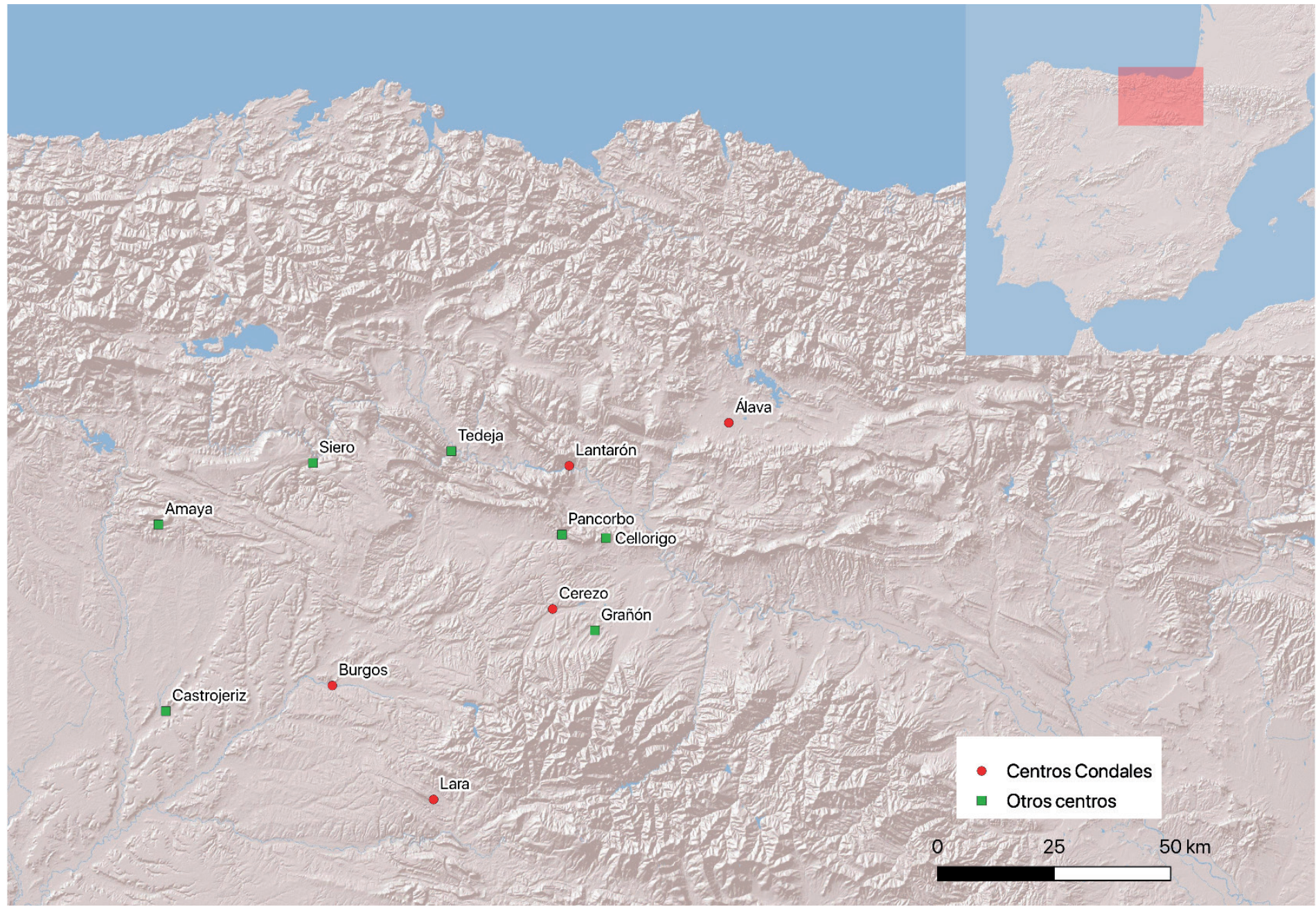

Figura 1. Localización de Lantarón en el conjunto del "sistema castellano".

de una arqueología de los estados altomedievales en sentido propio, a pesar de que se cuente con algunos trabajos relevantes sobre el área astur (Muñiz López y Gutiérrez González, 2004), o lugares centrales como Peña Amaya (Quintana López, 2017) o el Desfiladero de la Horadada (Lecanda Esteban, 2015). Muchas de las intervenciones realizadas son aún de baja intensidad, no siempre han proporcionado resultados suficientemente elocuentes o no se han llegado a publicar de forma detallada.

El objetivo de este trabajo será el de realizar un primer acercamiento a las dinámicas políticas de uno de los territorios que conforman las "castillas altomedievales" a partir de los registros arqueológicos que han sido construidos a lo largo de los últimos años, llevando a cabo una relectura parcial de la documentación escrita preservada. Para ello se ha elegido el territorio de Lantarón, documentado desde finales del siglo IX en el sector occidental de la actual provincia de Álava y el norte de Burgos, y que constituye uno de los territorios más pequeños del sistema castellano (fig. 1). El término de Lantarón ha sido recuperado en los años 70 para denominar una nueva entidad creada como resultado de la fusión de los municipios de Bergüenda y Salcedo, pero hay una neta discontinuidad toponímica y territorial entre el período medieval y el contemporáneo. A diferencia de otras unidades políticas castellanas articuladas en torno a un lugar central bien definido (p. ej. Castrojeriz, Burgos, Lara, Cerezo, Peña Amaya), un rasgo que caracteriza la morfología política de Lantarón y del contiguo territorio de Álava es su carácter polinuclear y difuso. Recurriendo a un enfoque multiescalar y comparativo se pretende analizar las formas de micropolítica, explicar la articulación de este entramado territorial, así como realizar una caracterización densa de los sistemas políticos altomedievales en sociedades carentes de centros urbanos y connotadas por fuertes identidades locales. 
SPAL 30.2

(2021)

\section{8-339}

ISSN: $1133-4525$ ISSN-e: 2255-3924
Este trabajo se divide en tres partes. En primer lugar se realiza una caracterización arqueológica de Lantarón utilizando un triple nivel de análisis: el área nuclear, el contiguo valle del Ebro en el tramo correspondiente con el desfiladero de Sobrón y el conjunto del territorio de Lantarón. En segundo lugar se analiza su funcionamiento en términos sociales y políticos durante los siglos IX y X, realizando algunas comparaciones con otros territorios próximos. Se concluye formulando algunas generalizaciones y propuestas para el futuro. No obstante, y de forma previa, se realizarán algunas breves consideraciones sobre el concepto de estado que se pretende utilizar en este trabajo y los problemas heurísticos que plantea su uso.

\section{EL ESTADO ALTOMEDIEVAL}

No cabe duda de que el empleo del concepto de estado, de bienes fiscales o la misma noción de lo público en la Alta Edad Media es problemático, y no existe un consenso entre los especialistas a la hora de recurrir a esta categoría analítica (Fuente, 2008). Los recelos proceden de aquellos que subrayan la existencia de una neta discontinuidad entre las formaciones políticas medievales y el estado moderno, el presentismo con el que se usa el término, o las propias características de los reinos altomedievales: carácter informal, formas de territorialización difusa, policentrismo, relevancia de los vínculos personales, etc. (Davies, 2003). En cambio, otros autores han sostenido la utilidad del concepto en términos analíticos, siempre que se basen en conceptualizaciones sólidas y rigurosas, evitando lecturas teleológicas e identificar en la Edad Media las genealogías de los estados nación modernos (Reynolds, 1997).

Con todo, ha sido Chris Wickham el autor que ha construido categorías más operativas y flexibles para estudiar los poderes centrales del período postromano en su clásica y monumental obra sobre Europa y el Mediterráneo (Wickham, 2005). Con el fin de favorecer los análisis comparativos, este autor ha definido dos modelos ideales contrapuestos que caracterizarían este tipo de formaciones políticas: los estados fuertes de base fiscal, que cuentan con un sistema impositivo más o menos generalizado y establecen una cierta distancia entre las aristocracias y el estado; y por otro lado, los estados débiles basados en la política de tierras, en los que el poder de los gobernantes se deriva de su riqueza patrimonial y su capacidad para gestar alianzas, estrategias u oposiciones mediante cesiones y expropiaciones de derechos y bienes, en particular de tierras. En este caso hay un vínculo poderoso entre aristocracias, gobernantes y el estado. Este autor indica, no obstante, que son modelos ideales en sentido weberiano y que por lo tanto hay numerosas gradaciones intermedias que combinan rasgos de ambos modelos (Wickham, 2005, pp. 56-59).

En los últimos años el debate se ha enriquecido mediante la incorporación de nuevas perspectivas. Una de las aportaciones más fecundas es la noción de enfoque relacional propuesta por Bob Jessop y aplicada recientemente al análisis de las sociedades altomedieval. De forma simplificada Jessop plantea que, más que una institución, un estado precapitalista es ante todo una serie de relaciones entre distintos agentes. La morfología, capacidad de acción y estructura que adoptan los estados dependen, por lo tanto, de la naturaleza de las relaciones que se establezcan entre los distintos sujetos políticos, así como de las bases materiales sobre los que se fundamentan estas relaciones (Jessop, 2016, pp. 97-179). Adoptando, de hecho, una posición pragmática, autores como B. Routledge han sugerido que más que pretender definir la noción de estado en 
SPAL 30.2

(2021)

308-339

ISSN: $1133-4525$ ISSN-e: 2255-3924 función de lo que es, sería más adecuado hacerlo en términos de procesos y prácticas políticas: el estado como efecto más que como entidad (Routledge, 2014). Por otro lado, tal y como ha subrayado B. Jessop la formación del estado no es un proceso único y definitivo, sino que ha sido construido y reconstruido muchas veces con sus altibajos, colapsos, centralizaciones, etc. (Jessop, 2007, p. 184).

Teniendo en cuenta estas perspectivas, en este trabajo se pretende analizar, desde una diversidad de escalas y perspectivas, las prácticas políticas que dieron lugar a la emergencia de un territorio de carácter condal en los siglos IX-X, examinando los distintos agentes implicados en este proceso, e intentando analizar por qué esta formación política tuvo una vida tan efímera recurriendo a planteamiento relacional.

\section{FORMAS Y GEOGRAFÍA DEL PODER EN LANTARÓN EN LOS SIGLOS IX Y X}

Un documento redactado el 18 de noviembre del año 897, hoy perdido pero transcrito en el siglo XVII, narra cómo el abad Juliano donó el monasterio de Unceca (valle de Mena) al de San Román de Tobillas (Valdegobía). En la cláusula regnante se especifica que el documento fue realizado reinando en Oviedo Alfonso y el comite Gundisalvo Telliz in Lantaron. Esta es la primera vez que se reporta la existencia de un conde en Lantarón. A partir de esta fecha y hasta el año 1040 hay un total de nueve referencias a varios personajes que aparecen vinculados a Lantarón o a Lantarón y otros lugares, como Término o Buradón, empleando un título condal. A partir de estas menciones los especialistas han identificado Lantarón como una de las territorialidades a cuya cabeza podía haber un personaje con un título condal, y uno de los cinco ejes principales de articulación del sistema condal de Castilla en los siglos IX y X (Estepa Díez, 2009). Y aunque en los últimos años se han realizado importantes aportaciones para definir la naturaleza política de este espacio, su articulación interna y la actividad de estos personajes (p. ej. Larrea Conde, 2007; Martín Viso, 2002; Santos Salazar, 2013), la verdad es que sigue resultando extremadamente difícil caracterizar de forma detallada Lantarón en la Alta Edad Media. La discontinuidad toponímica, las limitaciones de los testimonios textuales preservados, y sobre todo la entidad material de los lugares, determinan que se haya generado gran confusión a la hora de definir este territorio y su núcleo homónimo. Desde el siglo XVIII numerosos autores han pretendido ubicar un centro urbano, un castillo o un lugar central de una cierta entidad en Lantarón, proponiendo varias ubicaciones. Como en una cadena autorreferencial, las propuestas realizadas por los primeros autores han sido transmitidas una y otra vez hasta convertirse en certezas o en lugares comunes, perdurando hasta nuestros días.

En los últimos años se ha llevado a cabo una revisión crítica de estos presupuestos y se han realizado nuevos hallazgos arqueológicos que permiten sugerir nuevas interpretaciones (Quirós Castillo, 2020b). En esta sección se pretende analizar arqueológicamente el territorio de Lantarón en tres escalas diferentes: en primer lugar se intentará definir el área nuclear de Lantarón; a continuación se abordará el espacio situado en el Ebro y en el tramo del desfiladero de Sobrón; por último, se hará referencia al territorio de Lantarón (fig. 2). 
SPAL 30.2

$(2021)$

308-339

ISSN: $1133-4525$

ISSN-e: 2255-3924

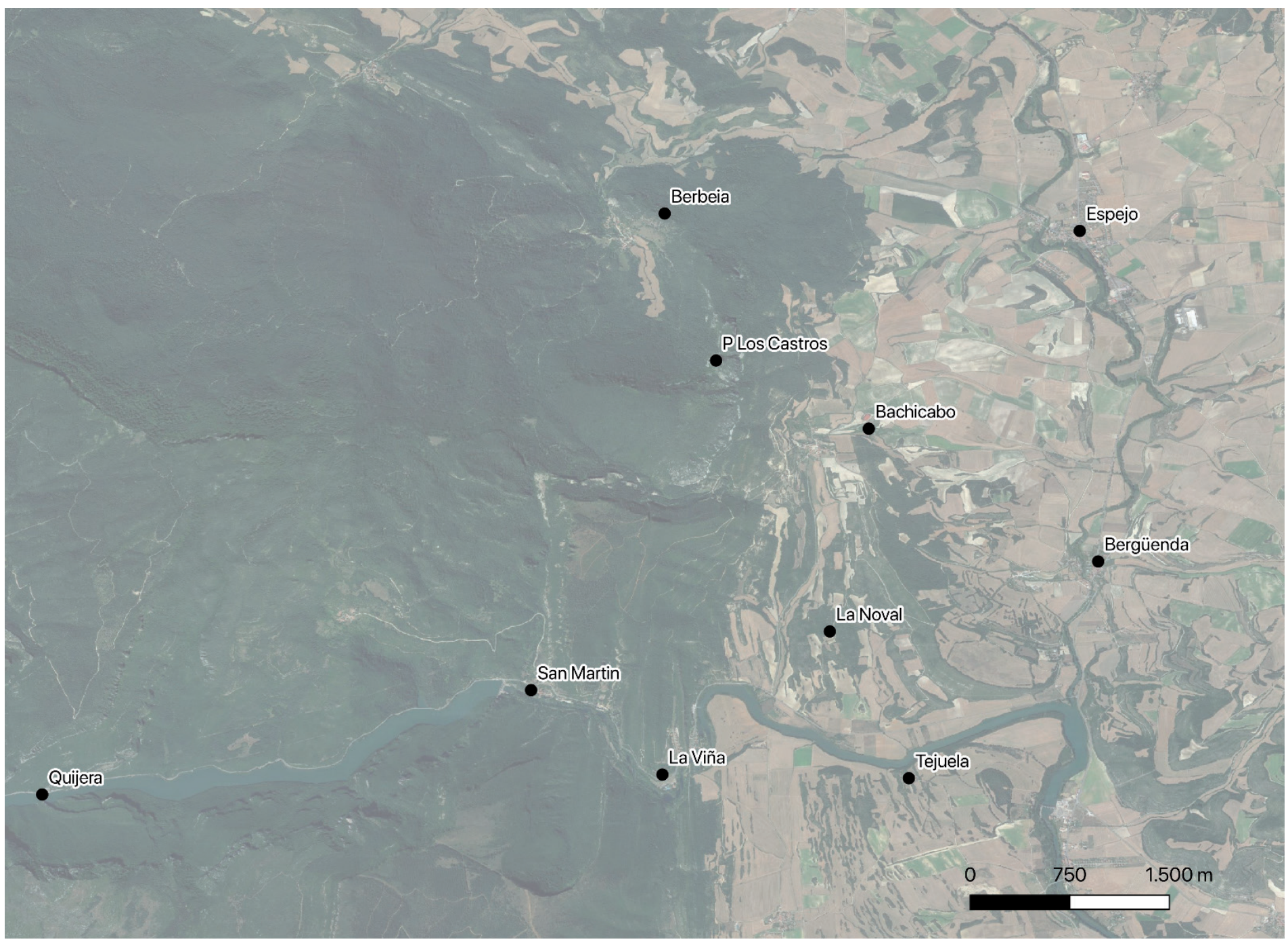

Figura 2. El área nuclear de Lantarón y el desfiladero de Sobrón.

\subsection{El área nuclear de Lantarón}

En octubre del año 1175 el monasterio de San Millán de la Cogolla llevó a cabo una pesquisa con el fin de identificar los bienes de realengo y de infanzón que había en Valdegobía y que, por lo tanto, quedaban exentos de ciertos pagos (Ledesma Rubio, 1989, n. 426, p. 315-320). El documento es de notable interés para conocer tanto la entidad de los bienes fiscales alli existentes, como otros aspectos básicos relativos a la articulación de Lantarón y de otras localidades del valle. Así por ejemplo, esta es la única vez que se menciona expresamente un castellum de Lhantaron, pero también se describen numerosos bienes con topónimos que aún se preservan, estableciéndose de esta manera un puente entre la documentación medieval y los paisajes actuales. Gracias a este listado detallado es posible saber que existió en la Plena Edad Media una localidad denominada Lantarón diferenciada de un castillo homónimo que se ubicaba en el espacio delimitado al sur por el río Ebro, al oeste por Sobrón, al norte por Bachicabo y al este por Bergüenda. De hecho, en este documento se cita en varias ocasiones la existencia de confines compartidos entre Lantarón, Bergüenda y Bachicabo. El pueblo de Lantarón vuelve a mencionarse en el testamento de Diego Gómez de Sarmiento, conde de Salinas, del año 1384 (Fernández de Palomares, 1979, p. 57), pero ya no aparece entre los bienes con los que su descendiente Pedro Sarmiento funda mayorazgo en 1442 (Urcelay Gaona, 2019, doc. 10, pp. 500-5). Por todo ello se puede inferir que el poblado de Lantarón pudo abandonarse en la primera mitad del siglo XV.

En este espacio, de unos $7 \mathrm{~km}^{2}$, se alternan en la actualidad áreas de cultivo extensivo, parcelas en barbecho y zonas de monte bajo, sin que se reconozcan restos construidos en alzado. Solamente en la zona conocida con el nombre de La Noval se han 
SPAL 30.2

(2021)

\section{8-339}

ISSN: $1133-4525$ ISSN-e: 2255-3924 identificado algunos indicios de interés arqueológico. En el lugar pueden observarse diversos derrumbes, aterrazamientos, materiales constructivos y paramentos montados a seco de gran grosor y longitud. El área se articula alrededor de un risco amesetado $(566 \mathrm{~m})$, que en gran parte ha sido deformado por la instalación de una torre de alta tensión y la creación de un espacio de cultivo (Alonso Martínez, 2014). Además, en la zona se han hallado cerámicas protohistóricas, alto y plenomedievales, así como materiales líticos que han permitido identificar una ocupación calcolítica y un despoblado medieval. El yacimiento fue catalogado en los años 90 por el Gobierno Vasco con la categoría de zona de presunción arqueológica con el nombre de Noval-Lantarón. No obstante, en la actualidad su visibilidad arqueológica es muy limitada y las prospecciones que hemos realizado a lo largo de los últimos diez años (2009, 2013, 2015, 2017, 2020) no han permitido recuperar un volumen significativo de materiales, ni definir en detalle la naturaleza de la ocupación. De la misma manera, otros focos de interés arqueológico situados en este espacio nuclear tampoco han proporcionado resultados muy alentadores. Este es el caso de San Juan, monasterio recordado en la citada pesquisa de 1175 en proximidad de la fuente de Lantarón y aún existente en el siglo XIX (Ruiz de Loizaga, 1979, p. 298). A pesar de que en Bachicabo aún se conserva memoria de la existencia de enterramientos en el lugar, la prospección no ha llevado a identificar materiales significativos. Lo mismo podría decirse respecto a la cercana localidad de San Miguel, o en lugares con topónimos tan sugerentes como Salas, Castrejón o Traspalacios (González Salazar, 1989). De todo esto se infiere que, bien por su agotamiento, bien por el impacto de las prácticas agrarias recientes, la lectura arqueológica en superficie de estos lugares está notablemente comprometida. Solamente la realización de intervenciones intensivas permitiría evaluar con mayor profundidad estas localidades. Esta escasa materialidad contrasta con la inusual concentración en toda esta zona, así como en la orilla opuesta del Ebro, de referencias en la documentación de los siglos X-XII a monasterios, iglesias, palatia, bienes aristocráticos o sernas. Además, estos documentos mencionan la actividad en la zona de personajes de notable entidad, como es el caso de Oveco Díaz (a.1028), el senior Flain Martinez (1084), Domina Elvira (1016), la reina Jimena de Pamplona (a. 1028) o un merino (1012).

En consecuencia, a la luz de los indicios disponibles se puede concluir que en la Alta y la Plena Edad Media existió una localidad conocida con el nombre de Lantarón al sur de la actual Bachicabo, en el actual término municipal de Valdegobía. Es muy probable que presentase, al menos en los siglos XI-XII, una morfología polinuclear articulada en una diversidad de polos atendiendo a los indicios disponibles. La presencia de espacios de representación, gestión y propiedad aristocrática es notable si se compara con los estándares conocidos en el área alavesa y castellana, pero no parece existir un centro o foco nuclear preeminente respecto a otros.

El castillo de Lantarón es una entidad claramente diferenciada del poblado de Lantarón. La existencia de un castillo en Lantarón se conoce únicamente a través de la mencionada pesquisa de 1175 y, de hecho, solamente los historiadores que han utilizado la documentación textual han sugerido que el lugar central de Lantarón sería una fortificación.

Desde el siglo XVIII hasta la actualidad la localización de Lantarón ha sido objeto de especulación por parte de numerosos autores, empezando por C. J. de Varona Sarabia (Inmaculada, 1943) que menciona la existencia de «muchas ruinas de edificios donde fue la ciudad de Lantarón» en el área de San Martín. Asimismo, el P. Flórez recoge la existencia de un «término llamado Lantarón y una ermita en un alto sobre 
SPAL 30.2 $(2021)$

308-339

ISSN: $1133-4525$ ISSN-e: 2255-3924

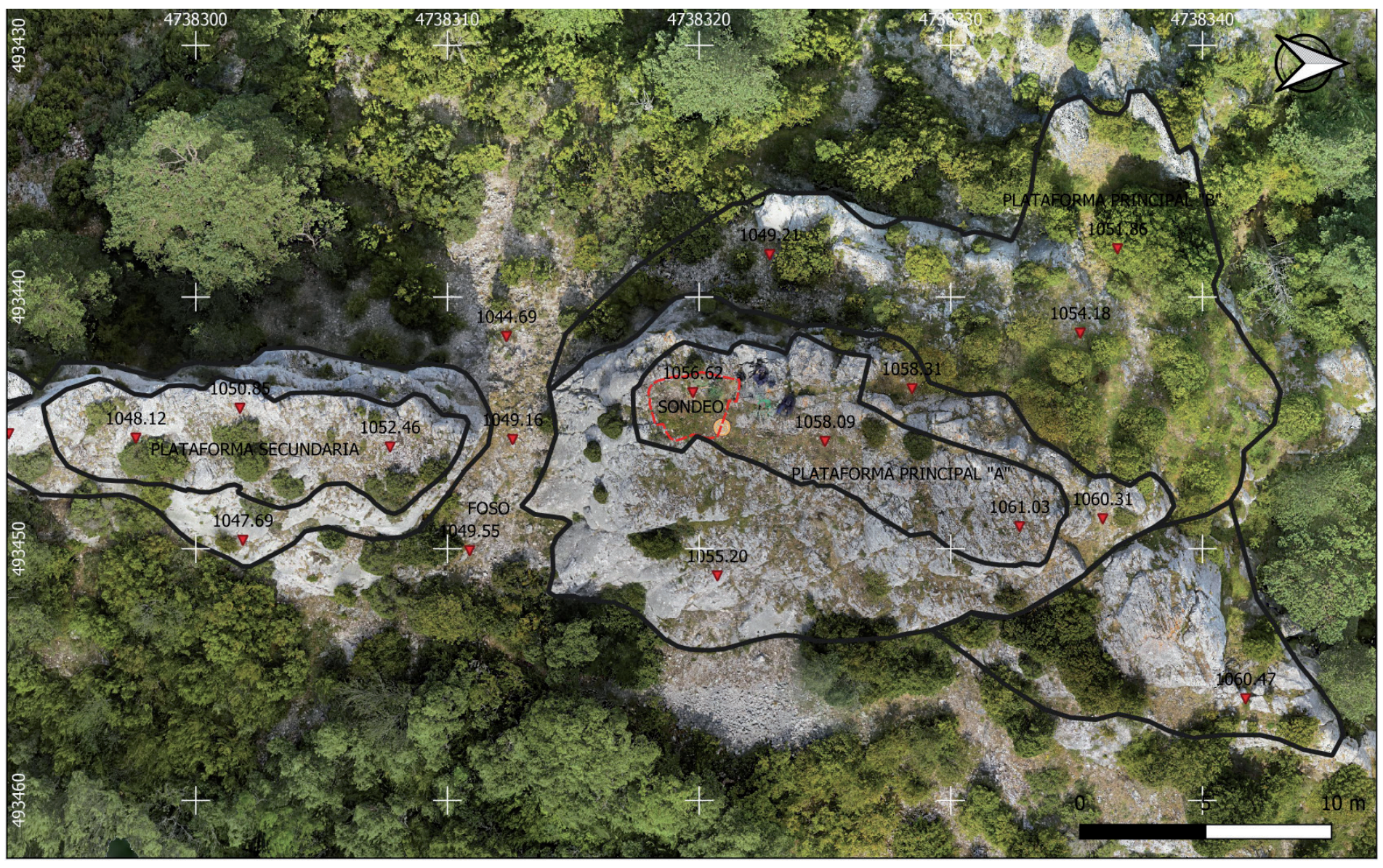

Figura 3. Ortofoto de la Peña Los Castros (Barrio-Bachicabo) y localización de los sondeos realizados en julio del año 2020.

el mismo rio que llaman S. Martín de Lantaron, distante 14 leguas de Burgos» (Florez, 1771). No obstante, fue J. J. De Landazuri a finales del siglo XVIII el que estableció un vínculo estrecho entre Sobrón y Lantarón, al afirmar que "Lantaron está ya arruinado, situado encima de Sobron y fue en lo antiguo perteneciente a Salinas de Añana" (Landazuri, 1798). Esta asociación se va a mantener a lo largo del siglo XIX por parte de J. A. Llorente, el Diccionario Geográfico-Histórico de la Academia de la Historia o el Diccionario Geográfico-estadístico de España y Portugal. A lo largo del siglo XX esta identificación se mantiene por parte de autores como R. Becerro de Bengoa, J. Pérez de Uriel, G. Martínez Díez (que llega a afirmar que en lo alto de uno de los riscos próximos todavía se divisan desde la carretera los restos de la fortaleza de Lantarón), M. Portilla, J. Caro Baroja, etc. (Becerro de Bengoa, 1918; Caro Baroja, 1983; Martínez Díez, 1981; Pérez de Urbel, 1945; Portilla Vitoria, 1984). En los últimos años se ha mantenido la asociación entre Lantarón y Sobrón pero se han propuesto también otras localizaciones (Alonso Martínez, 2014; Martín Viso, 2002; Sagredo, 2007).

Una prospección realizada por A. Martínez Velasco en la Peña Los Castros (Barrio-Bachicabo) ha permitido identificar una ocupación de altura compatible con una fortificación como la de Lantarón (fig. 3). Se trata de una agreste colina (1056 m) situada en el cordal que actúa como divisoria de aguas entre Bachicabo y Barrio, que domina el collado de Lahoz y en la que se han localizado algunos metales y materiales cerámicos alto o plenomedievales. Sus dimensiones son muy modestas (cumbre alargada de unos $15 \times 4 \mathrm{~m}$ ) y aunque no se preservan estructuras o paramentos en vista, si se han realizado algunas labores de regularización y adecuación de las pendientes rocosas. Los sondeos que hemos realizado recientemente han permitido recuperar un discreto número de materiales arqueológicos pleno y altomedievales, por lo que se considera que este yacimiento sería compatible con la documentada fortificación de Lantarón. 
SPAL 30.2

(2021)

\section{8-339}

ISSN: $1133-4525$ ISSN-e: 2255-3924

Por otro lado, sabemos que en el área nuclear de Lantarón ha habido más de un castillo. Un documento del año 1123 recuerda la existencia de un castillo de Berbeio. Berbeia es un importante yacimiento de la Edad del Hierro que fue reocupado en época medieval situado a más o menos de un kilómetro al norte de Peña Los Castros y a unos $4 \mathrm{~km}$ en línea recta del despoblado de Noval-Lantarón. Durante las excavaciones realizadas en los años 70 se identificaron toda una serie de niveles de ocupación y un silo altomedieval, así como los restos de una presunta torre sobre un risco (847 m) que han sido atribuidos a este período (Agorreta et al., 1975). Todavía hoy en día es posible reconocer materiales de este período en las laderas de esta colina. Como en el caso anterior, sus dimensiones son modestas y no se conservan paramentos o estructuras en alzado. Ambos emplazamientos se caracterizan, además, por tener una cuenca visual muy amplia.

Con independencia de que el yacimiento de Peña Los Castros se pueda identificar o no con el castillo de Lantarón, no cabe duda de que ha debido ser una fortificación modesta, destinada más a ser vista desde un amplio territorio que a desempeñar un papel ofensivo activo. Son centros de poder donde se expresa autoridad y legitimidad, y donde se construyen comunidades políticas. De hecho, sabemos que Berbeia en el siglo XII funciono como lugar de asamblea (a. 1123, Ruiz Asensio et al., 2010, n. 142, pp. 372373). En realidad, tampoco debe descartarse que Peña los Castros y Berbeia funcionasen en red, conformando un sistema defensivo y de representación múltiple. Es decir, este yacimiento presenta características similares a las de otros castillos altomedievales que se han identificado en varios sectores del norte peninsular, como es el caso de Buanga en Asturias (Fernández Conde y Fernández Fernández, 2010), el de Subiedes en Cantabria (Marcos Martínez y Mantecón Callejo, 2009) y el reino leonés (Gutiérrez González, 1995), así como otras fortificaciones más tardías del área vizcaína (García Camino, 2002). Precisamente, la escasa entidad de este tipo de fortificaciones ha determinado que sean de difícil identificación o resulten incluso invisibles en las prospecciones, salvo en aquellos casos en los que la persistencia toponímica haya permitido guiar el trabajo de campo o bien el lugar se haya mantenido en uso durante un largo período.

En conclusión, en el área nuclear de Lantarón se identifican una diversidad de polos, dotados con frecuencia de un elevado capital simbólico y social, aunque modestos en términos materiales, que definen un espacio político polinuclear. Esta morfología múltiple define tanto el lugar de Lantarón como en general, buena parte de su territorio.

\subsection{El desfiladero de Sobrón en el valle del Ebro}

Con el fin de profundizar en el análisis de esta estructura territorial centraremos ahora nuestra atención en las hoces de Sobrón. El área nuclear de Lantarón se sitúa inmediatamente al este de un profundo desfiladero de unos $8 \mathrm{~km}$ atravesado por el río Ebro, en el que se realizó en los años 50-60 el pantano de Sobrón. La presencia de fortificaciones y focos de poder en desfiladeros es un patrón bastante común en varios sectores castellanos durante la Alta Edad Media. Los ejemplos de Tedeja, Arganzón, Pancorbo o Buradón, entre otros, son algunos de los más relevantes en los que se han llevado a cabo intervenciones arqueológicas recientes (Aratikos, 2015; Lecanda Esteban, 2015).

En el tramo del río Ebro asociado al desfiladero de Sobrón se suceden toda una serie de yacimientos arqueológicos de distinta entidad que ilustran la estructura territorial de este espacio. Más concretamente centraremos la atención en cuatro de ellos, 
SPAL 30.2

(2021)

\section{8-339}

ISSN: $1133-4525$ ISSN-e: 2255-3924 ordenados de este a oeste: Santa María de Quijera, San Martín de Lantarón, Balneario de Sobrón y Tejuela.

3.2.1. La iglesia de Santa María de Quijera se menciona por vez primera en el año 913 en una generosa donación realizada por Elvira y su hijo Álvaro conservada en el cartulario de San Millán de la Cogolla. Son miembros de una familia activa a escala supralocal, puesto que disponen de bienes en Bergüenda y otras aldeas del río Omecillo. Con posterioridad Quijera fue agregada por el rey García de Nájera al monasterio de San Millán en el año 1045. No tenemos muchas noticias sobre la entidad del monasterio, aunque en el documento del siglo X se menciona tanto al abad Assur como a un collegium fratrum que alli habitan. Se trata, por lo tanto, de uno de los muchos monasterios privados en manos de laicos que han sido construidos en este territorio en la Alta Edad Media con varios fines que impregnan la documentación textual de fondos monásticos como los de Valpuesta, San Millán de la Cogolla y Oña. En el pasado han sido considerados como instrumentos fundamentales en la creación de lugares habitados y la introducción de nuevas prácticas sociales desde paradigmas como la repoblación y las presuras sobre espacios yermos (Ruiz de Loizaga, 1982), o bien la aculturación de los pueblos del norte y la colonización (García de Cortázar, 2005; Peña Bocos, 1995). En algunas raras ocasiones en las que se cuenta con estudios arqueológicos detallados y un dossier documental, como es el caso de San Román de Tobillas, se ha podido observar que estos monasterios han desempeñado un rol complejo en términos de construcción de poderes locales y petrificación de la riqueza (Azkarate Garai-Olaun, 1995; Larrea Conde, 2007). Pero quizás las principales limitaciones en términos arqueológicos para analizar en profundidad estos conjuntos se derivan del hecho de que aún carecemos de intervenciones extensivas, que permitan situar estas arquitecturas monumentales en un contexto espacial y social más amplio, al menos en el área de Lantarón. Y el monasterio de Quijera no es una excepción. Apenas se conservan hoy en día los restos de una parte de la iglesia, ya que el yacimiento ha sido muy afectado por la construcción del pantano antes mencionado. Quijera se ubica a orillas del embalse en una modesta altura $(515 \mathrm{~m}$ ), en proximidad de la carretera A2122 que une Sobrón con el Valle de Tobalina. En la actualidad solamente es visible el arranque de la bóveda de la nave del templo, que probablemente fue reconstruida en época moderna. Pero en ausencia de una excavación no resulta posible realizar una caracterización detallada del yacimiento.

3.2.2. San Martín de Lantarón es el único lugar del área y del desfiladero que ha preservado el topónimo de Lantarón. Es por ello que ya desde el siglo XVIII, han sido legión los autores que lo han identificado con una "ciudad" o un lugar central de Lantarón. Se trata de una colina amesetada de 516 m que domina el río Ebro, presidida por una pequeña iglesia dedicada a San Martín fechable en el siglo XII (fig. 4). Las laderas se encuentran aterrazadas, pero el conjunto ha sido notablemente alterado en época reciente como resultado de la construcción de toda una serie de barracones empleados por los constructores del pantano antes citado y por los edificios pertenecientes al actual núcleo de Sobrón Bajo.

Durante los años 2011 y 2012 se llevó a cabo una intervención arqueológica en el área de San Martín destinada a evaluar la entidad del yacimiento. Más concretamente se intervino en tres espacios principales: la colina situada al oeste de la iglesia (526 m), la meseta donde se ubica la iglesia actual (517 m) y la ladera oriental de la colina (fig. 5). 


\section{SPAL 30.2 (2021)}

\section{8-339}

ISSN: 1133-4525

ISSN-e: 2255-3924

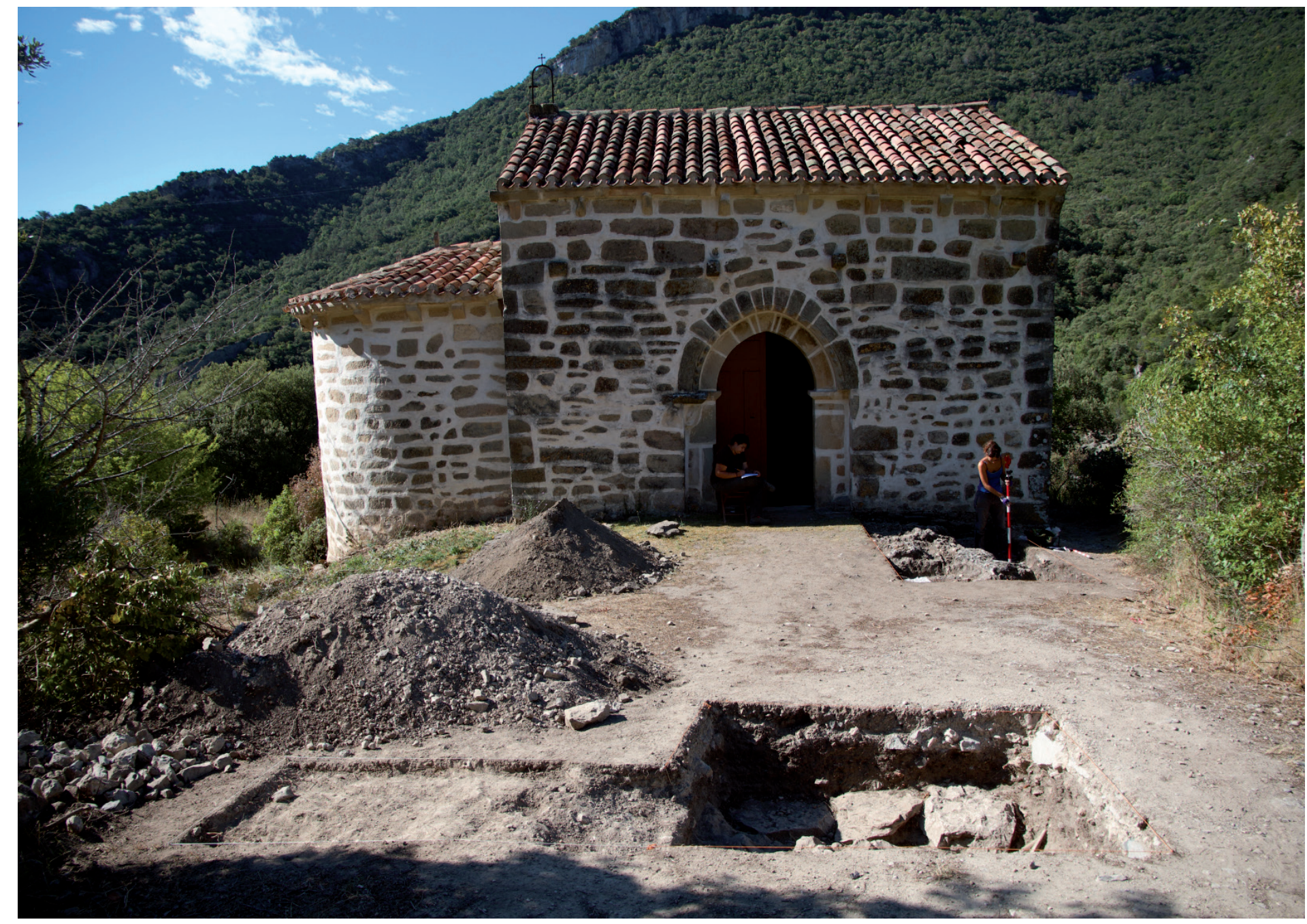

Figura 4. San Martín de Lantarón durante el proceso de excavación.

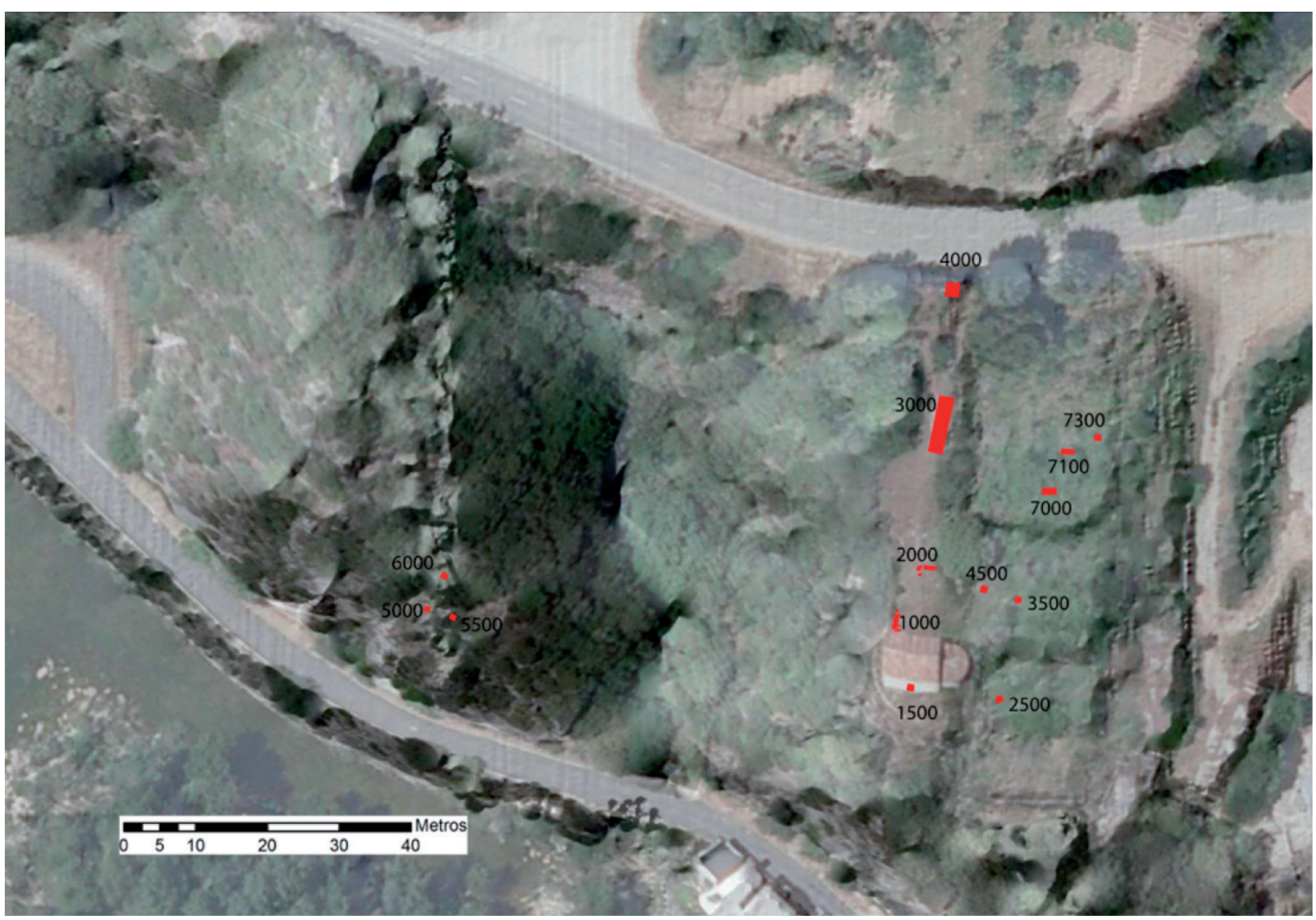

Figura 5. Planta de los sondeos realizados en San Martín de Lantarón en el año 2012. 
SPAL 30.2

(2021)

\section{8-339}

ISSN: $1133-4525$ ISSN-e: 2255-3924

En los tres sondeos realizados en la colina occidental se han recuperado tanto materiales protohistóricos atribuibles al Bronce Final-Hierro I, como una colección cerámica fechable en los siglos V-VI que incluye tanto TSHt como cerámica común realizada a mano y a torno. Y aunque la entidad de los depósitos conservados es modesta, se puede sugerir que se trata de una ocupación de altura que ha estado en uso tanto en la Protohistoria como en la época tardorromana, con un largo hiato intermedio. Presenta, pues, una secuencia similar a la observada en Astúlez (Sáenz de Urturi Rodríguez, 2011) y en cierto modo a la de Portilla (Solaun Bustinza, 2018).

En los doce sondeos realizados en el área de San Martín se ha observado la existencia de una neta división funcional entre la plataforma superior, donde se ubica la iglesia, y la ladera oriental. En la meseta superior se ha hallado un amplio cementerio formado por tumbas excavadas en la roca que cubre una superficie mínima de $1000 \mathrm{~m}^{2}$, en la que se ha construido la iglesia en el siglo XII. Las dataciones radiocarbónicas realizadas han permitido fechar el cementerio a partir del siglo VII (Quirós Castillo, 2012). En cambio, en la ladera occidental se han hallado varios suelos y niveles de ocupación de carácter doméstico que han podido ser fechados entre los siglos VII-XII. Mientras que los materiales cerámicos de cocina altomedievales, realizados en pastas groseras, son preferentemente de carácter local, la cerámica depurada ha sido realizada mayoritariamente con pastas procedentes del área alavesa, mostrando la inserción del yacimiento en una red de intercambios de una cierta entidad. No se han recuperado, en cambio, materiales importados de otros sectores castellanos, como pueden ser cerámicas pintadas en rojo, aunque un reducido número de materiales semidepurados son compatibles con las arcillas del alto valle del Ebro.

El ejemplo de San Martín de Lantarón testimonia, por lo tanto, la existencia de ocupaciones de altura a orillas del Ebro desde época tardorromana, así como la conformación de una comunidad rural estable a partir del siglo VII. Dos aspectos merecen la pena ser reseñados en este caso de estudio: por un lado, el micro-desplazamiento ocupacional que tuvo lugar entre los siglos VI-VII desde la colina occidental hacia San Martín (fenómeno que se observa en el caso de Astúlez y Santa Coloma, Sáenz de Urturi Rodríguez, 2011), y el abandono precoz del yacimiento, poco tiempo después de la fundación de la pequeña iglesia de San Martín. En definitiva, no es posible determinar si este templo llegó a desempeñar una función parroquial o tuvo otro significado.

3.2.3. El ejemplo de San Martín testimonia además que el desfiladero del Ebro estuvo densamente poblado en época altomedieval. De hecho, a poco más de $1 \mathrm{~km}$ hacia el este, donde el río Ebro ha excavado un meandro a la entrada de las Hoces, se localizaba el yacimiento de La Viña, en el lugar donde se ubica actualmente el "Hotel Blanco". El lugar fue objeto de excavaciones en 1866, identificándose dos conjuntos funerarios y algunos silos, aunque el segundo sector no ha podido ser localizado con precisión (Ortiz de Urbina, 1996, pp. 157-159). Se carece de descripciones detalladas de estos hallazgos, pero se sabe que en la necrópolis de La Viña se documentaron numerosas tumbas antropomorfas excavadas en la roca, tumbas delimitadas por lajas verticales y algunos sepulcros exentos (Trueba, 1871, pp. 134-136; Velasco y Fernández de Cuesta, 1879).

Más allá del evidente interés del topónimo Viña para referirse a un enclave situado en el seno del desfiladero, no cabe duda de que estos hallazgos confirman la notable densidad de ocupaciones próximas entre sí, así como la relevancia de las necrópolis depositarias de la memoria social de las comunidades locales. Otro aspecto relevante que hay que señalar es la coexistencia de distintas tipologías funerarias y el hallazgo de 
SPAL 30.2 $(2021)$

\section{8-339}

ISSN: $1133-4525$ ISSN-e: 2255-3924

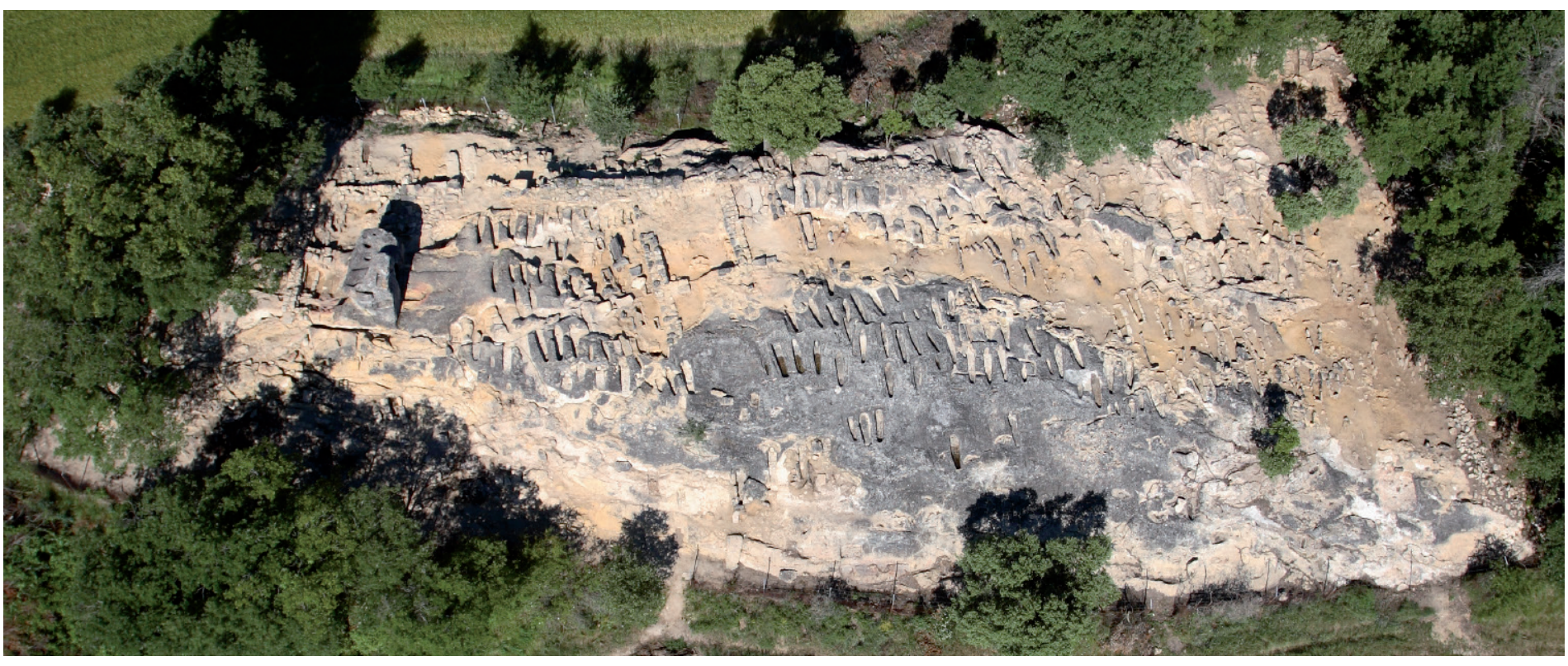

Figura 6. Fotografía aérea de la necrópolis de Santa Maria de Tejuela, según Aratikos.

sepulcros líticos exentos, bien documentados en conjuntos cercanos como es el de San Miguele en Molinilla (Gil Zubillaga y Sáenz de Urturi Rodríguez, 2001).

3.2.4. Pero quizás el yacimiento que ilustra mejor la centralidad de estas grandes necrópolis excavadas en la roca es el cercano despoblado de Santa María Tejuela, situado en la orilla opuesta del Ebro, en la actual provincia de Burgos (fig. 6). El yacimiento fue objeto de excavaciones sistemáticas por parte de A. Del Castillo en los años 60 del siglo pasado, lo que permitió reconocer un gran número de tumbas excavadas en la roca, un edículo rupestre y una iglesia emplazada en el centro del afloramiento rocoso en el que se ubica la necrópolis. Con posterioridad, se han llevado a cabo nuevas excavaciones en la necrópolis y en su entorno más inmediato. El número de enterramientos conocidos asciende a 340, un tercio de los cuales han conservado restos humanos, incluyendo tumbas antropomorfas excavadas en la roca y otras delimitadas por lajas. La cronología atribuida a este conjunto funerario se centra entre los siglos VII-VIII y XI, aunque sabemos que el poblado estuvo en uso durante la Plena Edad Media y se despobló antes del siglo XIV (Aratikos, 2015). En los sondeos realizados en proximidad del cementerio se han hallado algunas construcciones de carácter doméstico (edificios semiexcavados con zócalos de piedra) asociadas a numeroso material cerámico altomedieval fechado entre los siglos VIII-XI. Entre ellos destaca el hallazgo de un reducido lote de cerámicas pintadas en rojo probablemente procedentes del área del alto Ebro, así como un broche liriforme relacionado con las fases iniciales del yacimiento (Aratikos, 2015).

En conclusión, los cuatro yacimientos del desfiladero de Sobrón analizados muestran dinámicas que son representativas de las sociedades locales de Lantarón en términos de densidad poblacional, transformaciones de la red de poblamiento, articulación de las comunidades y estrategias de distinción. Pero para profundizar en estas dinámicas es necesario realizar un ulterior salto de escala.

\subsection{Del área nuclear al territorio de Lantarón}

Por motivos de espacio no será posible realizar una caracterización exhaustiva de la arqueología del entero territorio de Lantarón, por lo que solamente se presentarán de forma breve algunos rasgos distintivos. La primera dificultad a la que nos enfrentamos 


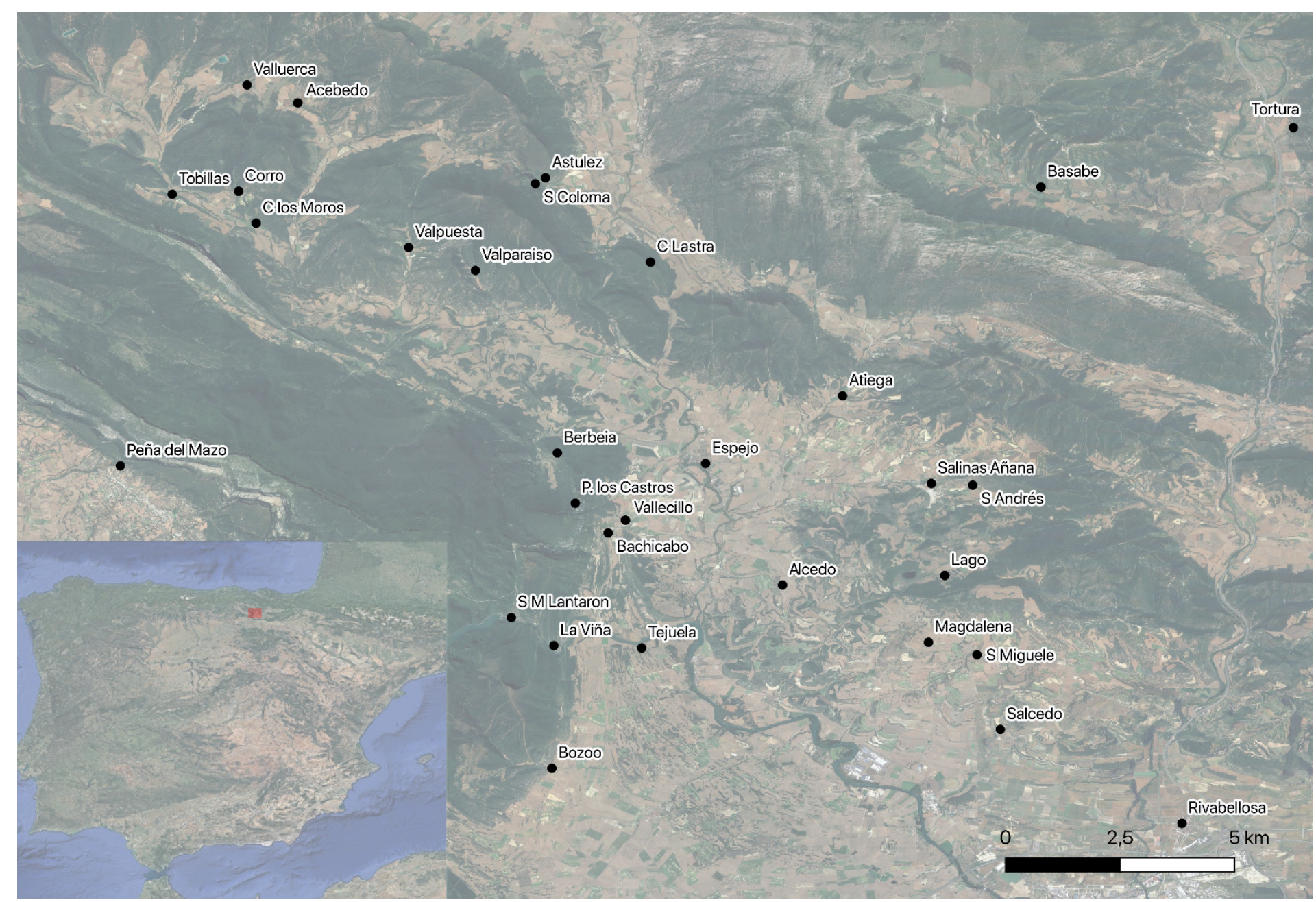

Figura 7. Principales localidades del territorio de Lantarón mencionadas en el texto.

para llevar a cabo esta labor es establecer los límites del territorio de Lantarón en la Alta Edad Media. Algunos autores han adoptado una perspectiva geográfica, incluyendo tanto el valle del río Omecillo como la cuenca de Miranda de Ebro a partir de las fuentes preservadas (Peña Bocos et al., 1998, p. 208). En cambio, en los últimos años se ha impuesto una caracterización contextual más que geográfica. Así por ejemplo I. Santos Salazar ha señalado que el condado de Lantarón tiene unos «límites inestables, identificables únicamente a través del espacio de acción social, política y económica de los grupos que reconocen la autoridad de un personaje que se titula conde en Lantarón» (Santos Salazar, 2013). Y aunque en realidad aún no se puede saber si hubo un territorio de Lantarón antes de que existiesen personajes así titulados, en esta ocasión nuestro análisis se centrará fundamentalmente en la actual cuadrilla alavesa de Añana (693 $\mathrm{km}^{2}$ ), que incluye los términos municipales de Añana, Armiñón, Berantevilla, Iruña de Oca, Kuartango, Lantarón, las dos Riberas, Valdegobía y Zambrana. Más concretamente son cinco los criterios que se tomarán en cuenta: las dinámicas poblacionales, las identidades locales, las estrategias de distinción, las formas de conectividad y la geografía de los focos de autoridad (fig. 7).

3.3.1. Hasta la fecha no se han llevado a cabo excavaciones extensas en despoblados ni intervenciones programadas en lugares aún habitados. No obstante, los resultados de varios proyectos preventivos y de otros estudios puntuales muestran que el poblamiento altomedieval se estructuraba en Lantarón de forma distinta a la actual. Tanto en el fondo de valle como en las colinas se han documentado numerosas ocupaciones que definen un patrón mucho más denso y disperso del actual. Esta red de poblamiento se ha configurado y transformado de forma dinámica a lo largo de toda la Alta Edad Media, adoptando morfologías muy distintas entre sí. Se pueden atribuir al primer período postromano 
SPAL 30.2

(2021)

\section{8-339}

ISSN: $1133-4525$ ISSN-e: 2255-3924

ocupaciones de altura (colina occidental de San Martín, Astúlez, quizás Peña del Mazo en el contiguo valle de Tobalina), así como ocupaciones "dispersas" (Vallecillo) u otras asociadas a espacios funerarios como San Miguele (Quark, 2017, pp. 202-207). En el curso de los siglos VII-VIII se produjo una notable intensificación de la ocupación como resultado de la conformación de lugares nucleados en lugares como San Andrés, Santa Coloma, Tejuela, Fuentepudia (Quark, 2017, pp. 206-216) y quizás Tobillas y la cueva de los Moros, en Corro. Probablemente a lo largo de los siglos IX-X se fundaron otros núcleos, como son los casos de Acebedo, Castros de Lastra y quizás Villanueva de Valdegobía y Lago. Otras localidades indagadas en los últimos años, como Arenas en Tobillas (Quark, 2017, pp. 221-225), San Martín de Valparaíso y otros conjuntos rupestres o funerarios (p. ej. la Magdalena), carecen de cronologías precisas. Estas tendencias tienen su correlato en la abundante documentación textual preservada (Ruiz de Loizaga, 1982).

Por otro lado los registros paleoambientales disponibles, y en particular los del Lago de Arreo, permiten establecer algunos matices a este cuadro. El análisis geoquímico, palinológico y las variaciones de los niveles lacustres han permitido establecer que en los primeros siglos de la Alta Edad Media se produjo un retroceso de la actividad ganadera y una recuperación de la cubierta forestal. En los siglos VIII-IX tuvo lugar un incremento de la presión antrópica, que se manifiesta en un aumento de los espacios cultivados, una reducción del polen arbóreo y en el uso del fuego para la creación de nuevos terrazgos. No obstante, el período de mayor intensidad agraria se documenta entre el siglo $X$ y el XII, momento en el que se acentúa la deforestación y la expansión de los espacios cultivados (Corella et al., 2013, p. 565).

En definitiva, se pueden identificar tres etapas principales en las transformaciones del poblamiento y los paisajes de Lantarón a lo largo de la Alta Edad Media a la luz de la arqueología: nuevas fundaciones siguiendo patrones ocupacionales de baja intensidad en los siglos V-VI; tendencia a la nucleación y transformación de las prácticas agrarias en los siglos VII-VIII; mayor presión sobre el medio y creación de nuevos núcleos a lo largo de los siglos IX-XII. Por lo tanto, el paradigma que defiende la existencia de procesos de colonización o repoblaciones basadas en presuras no pueden ser ya sostenidas. De hecho, en los últimos años los especialistas en los textos han enfatizado el carácter retórico de estas narrativas a la hora de legitimar prácticas de apropiación (Larrea Conde y Viader, 2005).

3.3.2. Otro rasgo que caracteriza este territorio es la existencia de fuertes identidades locales, tal y como muestran no solo la morfología de los lugares habitados, sino sobre todo las prácticas y las geografías funerarias. En la cercana llanada alavesa raramente se ha llegado a constatar una correlación espacial simple entre lugares de habitación y espacios funerarios durante la Alta Edad Media. Algunos cementerios, aparentemente carentes de núcleos habitados asociados como podría ser el caso de Dulantzi o Aldaieta, perduran durante largos períodos de tiempo, a la vez que las primeras aldeas documentadas desde el siglo VII y VIII parecen carecer en las primeras etapas de necrópolis. La emergencia de nuevos núcleos de población no transformó de forma inmediata los mecanismos de construcción de la memoria social y la identidad de las colectividades. Se mantuvieron en uso las necrópolis previas dotadas de un indudable significado social, en torno a las cuales se han ido construyendo identidades colectivas de grupos no co-residentes. Solamente en una fase más avanzada el capital ideológico y social de las viejas necrópolis se desplazó a los emergentes espacios funerarios que se fueron consolidando dentro de aldeas como Zornoztegi, Zaballa, Gasteiz u otras (Quirós Castillo, 2020c). 
SPAL 30.2

(2021)

\section{8-339}

ISSN: $1133-4525$ ISSN-e: 2255-3924

En cambio, en el área del condado de Lantarón los núcleos habitados cuentan desde etapas tempranas con espacios funerarios, tal y como se observa en lugares como San Martín de Lantarón, Santa María de Tejuela, Santa Coloma, Peña del Mazo, probablemente San Miguele y quizás también en varios conjuntos rupestres y otras localidades. Como consecuencia de todo ello, el proceso de agregación y construcción de las sociedades locales en Lantarón siguió derroteros muy diferentes respecto a los documentados en otros sectores alaveses. Por todo ello se puede sugerir como hipótesis de trabajo que, tanto la precoz identidad entre comunidad funeraria y comunidad doméstica, como la resiliencia de perduración de esta identidad deben de considerarse como un marcador de cohesión y solidez de los lazos entretejidos en torno a una memoria social de larga duración. Si se acepta esta premisa, se podría plantear que las comunidades de Lantarón tendrían una mayor cohesión que las de la llanada alavesa. Y probablemente esta conclusión podría hacerse extensiva a la Rioja Alavesa y otros espacios próximos.

3.3.3. Esta fuerte cohesión local, quizás reforzada por la centralidad que han tenido los bienes comunales en las economías locales de la Alta Edad Media (Carvajal Castro, 2017; Martín-Viso, 2020) asi como la posesión de molinos y otros recursos como las iglesias (Quirós Castillo 2020a), habría determinado cuál ha sido la escala de la acción política a escala local, al menos hasta el siglo X. La notable localización de los horizontes políticos explica la naturaleza de las estrategias a las que han recurrido los poderosos y las minorías dirigentes a la hora de establecer relaciones sociales asimétricas, así como las diferencias existentes respecto a otros sectores alaveses.

Tres son los rasgos materiales a través de los que se materializan estas estrategias. Por un lado, la existencia de ocupaciones de altura y de lugares fortificados. Es cierto que las ocupaciones de los siglos V-VII de Portilla, Bilibio, San Martín de Lantarón o Astúlez son aún de difícil caracterización, pero resulta llamativa su completa ausencia en la llanada alavesa. Por otro lado, aunque la carencia de intervenciones intensivas en lugares fortificados como Berbeia, Peña los Castros o Término no ha permitido identificar niveles de ocupación de los siglos IX o X, se cuenta con indicios suficientes como para pensar que estas localidades hayan podido estar en uso en este período. Nuevamente, en la llanada alavesa las fortificaciones de estos siglos son totalmente desconocidas.

En segundo lugar, la mayor parte de los monasterios e iglesias altomedievales preservadas en Álava (fig. 8) se concentran en el área del condado de Lantarón, en el sector meridional del territorio y en el entorno de Acosta (como por ejemplo las iglesias de Tobillas, Korres, Atiega, Bachicabo, Añana, Rivabellosa, Valluerca, Urbina de Basabe, Marinda o Tortura; ver Sánchez Zufiaurre, 2007). Las edificaciones eclesiásticas de los siglos IX y X conocidas hasta la fecha (grupos 1 y 3 de Sánchez Zufiaurre) son edificios de cantería de alta calidad constructiva, promovidos por propietarios religiosos y laicos activos a escala supralocal o subregional, que invierten notables recursos en su realización con fines diversos: crear o reforzar relaciones de dominación a escala local; obtener derechos de vecindad, y por lo tanto, acceder a las divisas y a bienes de uso colectivo; blindar el patrimonio familiar frente a tendencias centrípetas; establecer relaciones clientelares; etc. (Carvajal Castro y Narbarte Hernández, 2019; Larrea Conde, 2007). A fin de cuentas, la riqueza en la Alta Edad Media no era un fin en sí mismo, sino un medio para obtener y reforzar el poder social (Godoy, 2019). Estos centros se conforman como islas de autoridad que se superponen a una realidad social articulada en comunidades dotadas de una fuerte identidad. 
SPAL 30.2

$(2021)$

\section{8-339}

ISSN: $1133-4525$ ISSN-e: 2255-3924

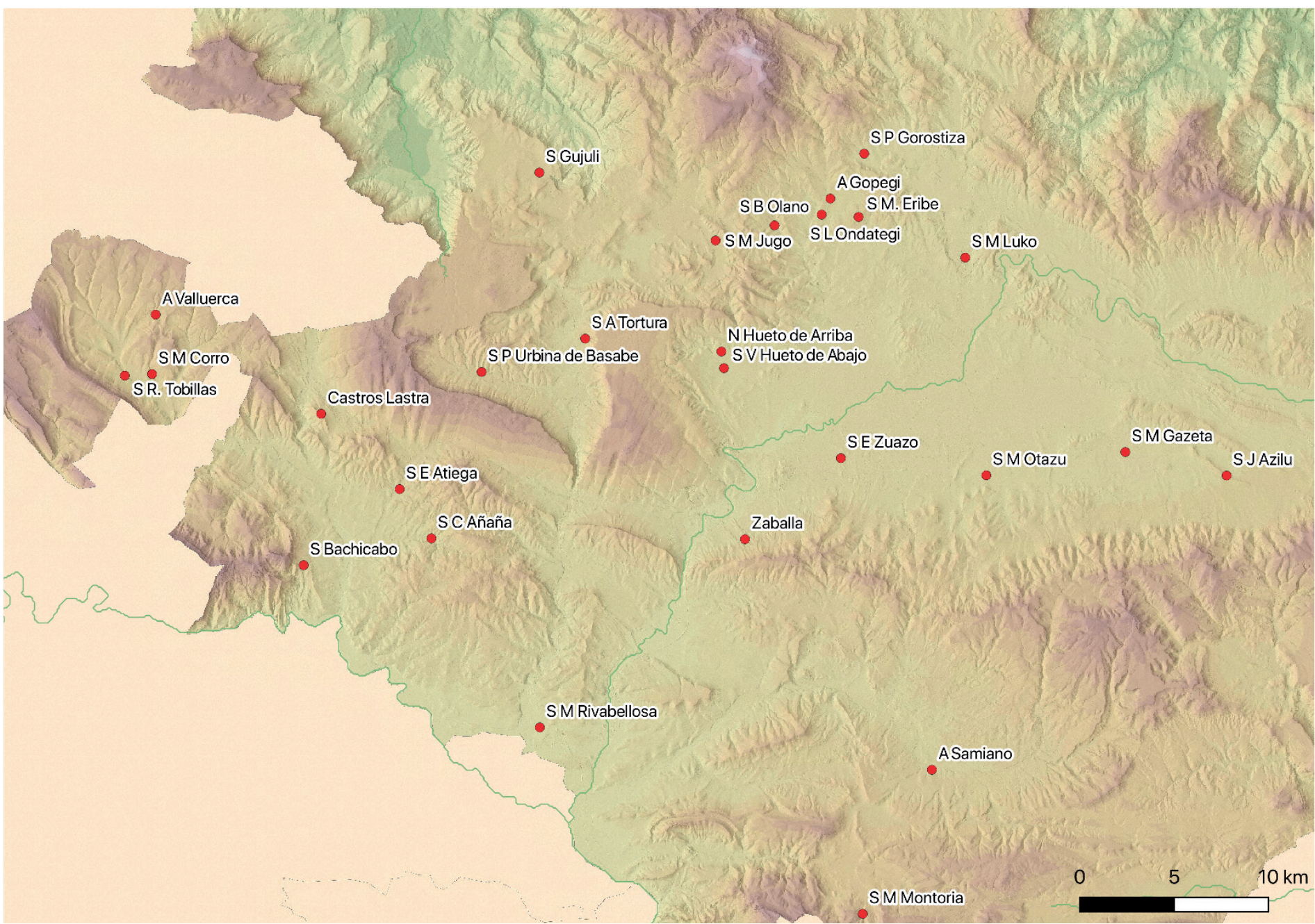

Figura 8. Localización de las iglesias altomedievales conservadas en alzado en el oeste de Álava.

A partir del siglo X se documenta un nuevo grupo de iglesias locales. En términos materiales ha sido posible identificar un conjunto de edificios realizados con técnicas de albañilería (grupo 2), que podría estar mostrando la presencia de nuevos agentes activos a una escala más localizada (Sánchez Zufiaurre, 2007). Pero también la documentación escrita ilumina la existencia a partir de este período de iglesias en Lantarón, en manos de comunidades locales y/o líderes aldeanos. Muchas de estas iglesias se recuerdan a lo largo del siglo $X$, cuando se donaron a potentes monasterios. En cambio, estas iniciativas son prácticamente desconocidas en la llanada alavesa antes del siglo X. ¿Podrían identificarse estas construcciones con las iglesias de cantería halladas en los últimos años, o en cambio habría que pensar que estas iglesias habrían sido realizadas con materiales efímeros, tal y como han propuesto algunos autores (García de Cortázar, 2018; Sánchez Zufiaurre, 2007)? En un trabajo reciente hemos sostenido que una identificación mecánica y simple entre determinados grupos sociales y técnicas constructivas es muy arriesgada, especialmente teniendo en cuenta el carácter multifuncional de estas arquitecturas (Quirós Castillo, 2020a).

Por otro lado, las excavaciones realizadas en lugares como Tobillas o Atiega han mostrado que muchas iglesias de cantería han sido realizadas sobre construcciones domésticas más antiguas, de tal forma que estos templos son una adición a un paisaje poblacional y social ya consolidado. La presencia, además, de tumbas de privilegio en Tobillas (García Collado, 2013), Aistra o Ulibarri-Arana, refleja la relevancia de estos templos a la hora de construir identidades aristocráticas ya desde el siglo IX. En definitiva, las iglesias propias altomedievales alavesas han constituido instrumentos poderosos de apropiación, legitimación y penetración señorial en un medio social muy compacto. A partir del siglo X las élites locales han construido iglesias locales, probablemente imitando el lenguaje político de los poderes supralocales. La concentración de estos 
SPAL 30.2

(2021)

308-339

ISSN: $1133-4525$

ISSN-e: 2255-3924

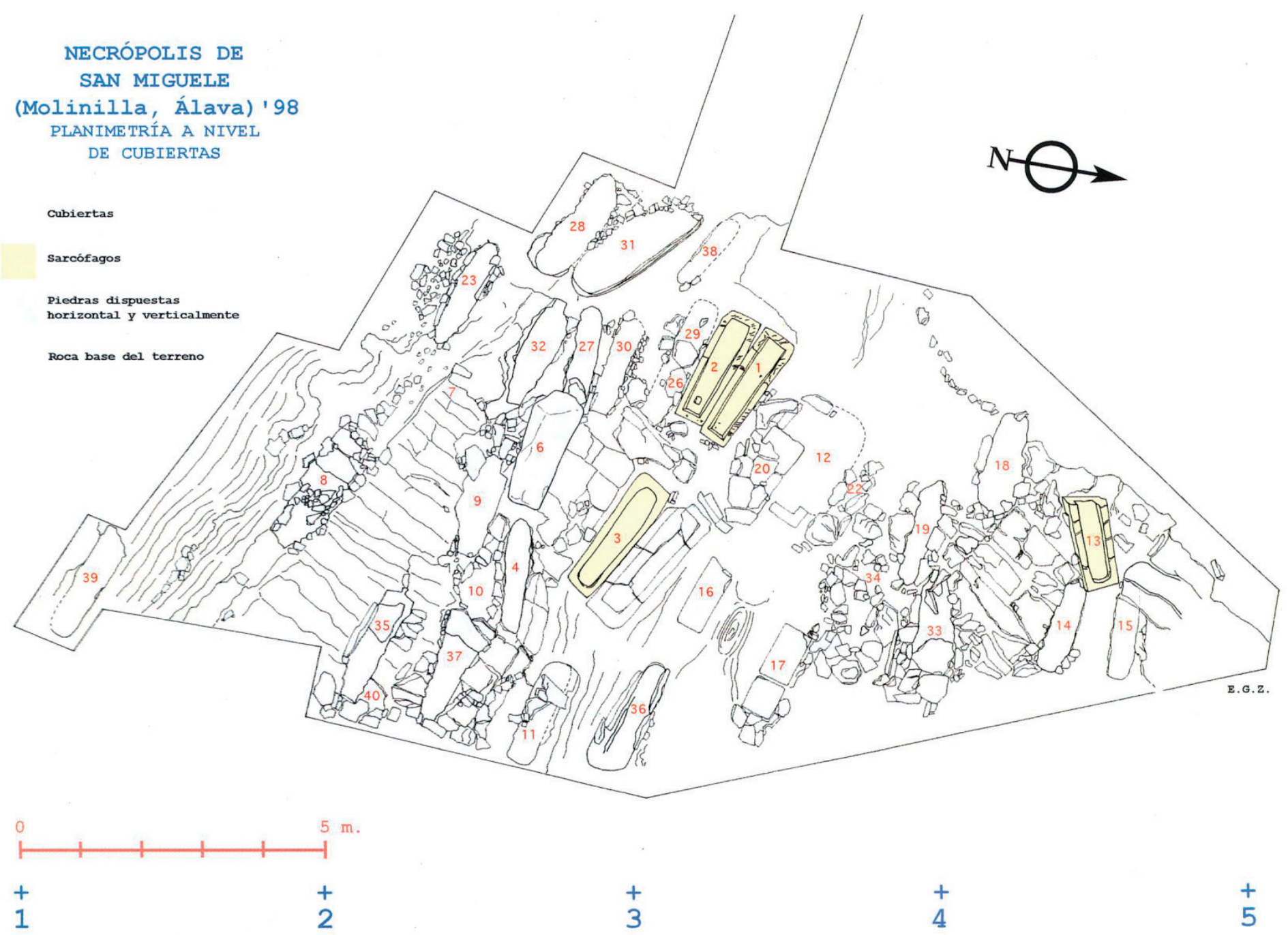

Figura 9. Necrópolis de San Migueles, según L. Gil.

centros de culto en el área de Lantarón respecto al área alavesa debe tenerse en cuenta a la hora de estudiar las prácticas políticas a escala local, y podría reflejar la existencia de muchos grupos pequeños en competición.

En tercer lugar, un rasgo que caracteriza los conjuntos funerarios altomedievales de este territorio es la presencia significativa de sarcófagos, tal y como se observa en los casos ya mencionados de San Miguele o La Viña (fig. 9). Son, además, muy comunes en la cercana cuenca de Miranda, donde un tercio de las necrópolis medievales conocidas cuentan con sepulcros (Campillo Cueva, 1996), o en el sector meridional de Álava, como es el reciente hallazgo de Korres (Leorza Álvarez de Arcaya, 2011) o los hallados en Payueta en el siglo XVIII (Ortiz de Urbina, 1996, p. 81). En cambio, su número es aparentemente muy reducido en el área nuclear alavesa, donde hasta la fecha se han hallado en pocos sitios de cronología tardoantigua, como es el caso de Dulantzi (Alfaro et al., 2019). El recurso a estas estrategias de distinción a lo largo de los siglos IX-XI debería de interpretarse en términos de una acusada competitividad social en las escalas locales en las que estos cementerios concentran la memoria y la identidad de la comunidad. Cabe entonces preguntarse si estos sepulcros identificarían aristocracias supralocales residentes en comunidades rurales o élites aldeanas locales, asimilables a los presbíteros que aparecen en las fuentes del siglo $X$ liderando algunas sociedades locales (Quirós Castillo, Santos Salazar, 2012). Teniendo en cuenta que los límites sociales en las comunidades altomedievales son bastante difusos (Álvarez Borge, 1987, p. 149), resulta difícil responder de forma tajante a este interrogante. Lo que no cabe duda es que los hallazgos de sarcófagos se concentran en el valle del Ebro, incluyendo el área de Tedeja (Lecanda Esteban, 2015). 
SPAL 30.2

(2021)

\section{8-339}

ISSN: 1133-4525 ISSN-e: 2255-3924
3.3.4. De hecho, el valle del Ebro constituye un eje fundamental de conectividad entre Castilla, Álava y el territorio de Lantarón. Los estudios sobre la proveniencia y las pautas de consumo de la cerámica altomedieval del área alavesa realizados en los últimos años (Azkarate Garai-Olaun y Solaun Bustinza, 2016; Grassi y Fornacelli, 2018; Solaun Bustinza, 2005) proporcionan algunos indicios importantes para comprender las formas de integración económica, política y social existentes entre algunas de las piezas que componen el complejo puzle castellano de los siglos VIII-X. Es cierto que los conjuntos cerámicos disponibles son aún limitados y que los estudios se han centrado más en la identificación de los lugares de producción y las características de las producciones consumidas que en los mecanismos de intercambio.

Una de las principales conclusiones que se ha obtenido es la existencia de una notable compartimentación de los patrones de consumo cerámicos en la Alta Edad Media, de tal forma que se han identificado cuatro subregiones: la Rioja Alavesa, el área vizcaína, Álava nuclear y el sector occidental o de Lantarón. Y aunque no todos los sectores están igualmente representados, es posible identificar diferencias significativas tanto en lo que se refiere a las formas de consumo como a las áreas de abastecimiento. En el caso específico de Lantarón se ha constatado un predominio de producciones de materiales de carácter local, que se han asociado principalmente a talleres de carácter doméstico (Solaun Bustinza, 2005). A este cuadro se podrían incorporar algunos matices, puesto que, en los yacimientos situados a orillas de Ebro, como es el caso de San Martín de Lantarón o Tejuela, llegan a ser comunes las formas procedentes del área alavesa y, de forma más puntual, del alto valle del Ebro, especialmente en lo que se refiere a la cerámica depurada. En cambio, los patrones de consumo en Álava, la Rioja Alavesa o Vizcaya muestran otros universos comerciales, caracterizados por la coexistencia de una diversidad de modelos de producción y de mecanismos de redistribución.

Presentan una problemática diferente las producciones decoradas con pintura en rojo, que aparecen siempre en porcentajes muy limitados y en lugares muy señalados. Son, indudablemente, materiales importados que tienen un significado más social y político que comercial, como todos los objetos de lujo (Wickham, 2005, pp. 694-695). Los estudios arqueométricos más recientes han mostrado que es posible atribuirlos a una diversidad de centros productivos que estarian localizados preferentemente en el alto valle del Ebro (Grassi, Fornacelli, 2018). Su distribución es desigual, tanto en términos cuantitativos como geográficos, y podrían relacionarse con la existencia de una demanda puntual de carácter aristocrático con carácter no comercial. Es decir, su distribución debería de explicarse en términos de reciprocidad, construcción de relaciones clientelares y/o de intercambio de regalos. En el área de Lantarón se han hallado en lugares como Tejuela, Berbeia, San Cristobal en Añana y Tobillas, o en localidades próximas como son Tedeja, Peña del Mazo, El Pópilo, Pancorbo o Artzinega, mientras que su presencia es aún más limitada en otros sectores alaveses (fig. 10). Además, es posible que su número se reduzca a partir del siglo $X$.

En definitiva, el horizonte del comercio utilitarista en Lantarón parece estar ceñido a un ámbito más local que el que se observa tanto en Álava nuclear como en la Rioja Alavesa, por lo que despunta aún más el hallazgo de cerámicas de prestigio en determinados núcleos procedentes del área castellana. Se puede sugerir, por lo tanto, que esta cerámica sería una manifestación de la participación en redes de relaciones sociales supralocales y/o supraregionales. 
SPAL 30.2 $(2021)$

\section{8-339}

ISSN: $1133-4525$ ISSN-e: 2255-3924

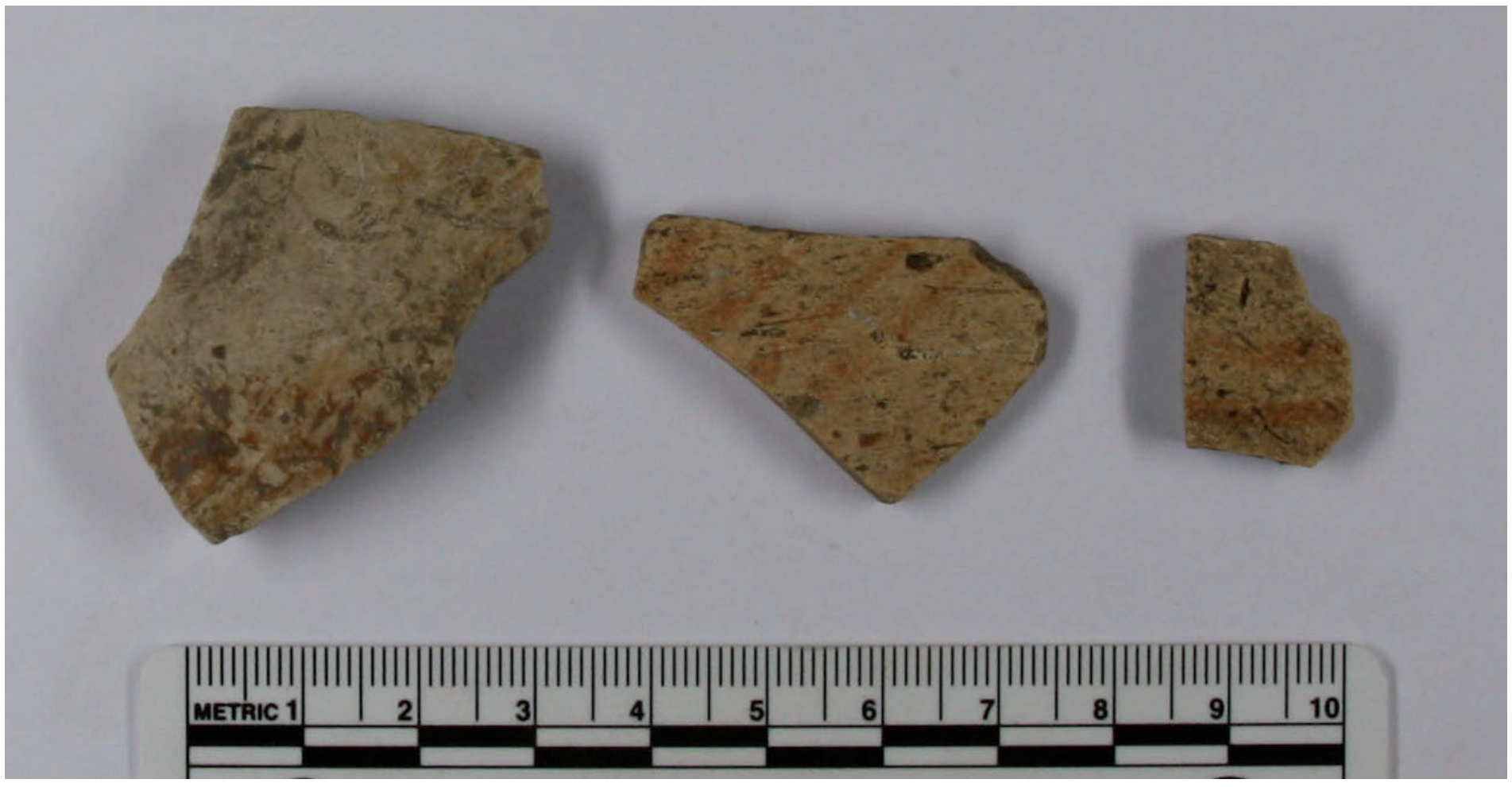

Figura 10. Cerámica pintada en rojo procedente de Berbeia (Barrio, Álava).

3.3.5. El último rasgo que caracteriza Lantarón, aunque no es una particularidad exclusiva de este territorio, es la estructura polinuclear de su geografía política. No obstante, este patrón alcanza en este territorio su máxima expresión. El "sistema castellano" altomedieval es un espacio político líquido (en sentido de Bauman) y heterogéneo, difícil de modelizar. Mientras que algunos de los territorios que lo conforman parecen bascular en torno a algunos lugares centrales, como puede ser el caso de Peña Amaya, Burgos, Cerezo o Lara, en otras ocasiones nos encontramos con realidades mucho más difusas basadas en un cierto número de focos de autoridad caracterizados por una diversidad de morfologías, dimensiones y funciones (Quirós Castillo y Santos Salazar, 2015). Además, la relevancia de estos polos va cambiando a lo largo del tiempo, conformando una red que está en permanente transformación. La civitas romana de Espejo, identificada por algunos autores con Uxama Barca (Plata Montero, 2008), no parece tener continuidad como tal en la Alta Edad Media, mientras que las civitates de Revendeca y Miranda, mencionadas en las Crónicas del siglo IX y localizadas presuntamente en Lantarón, no parece que hayan desempeñado un papel muy relevante a partir del siglo IX. Entre finales del siglo IX e inicios del siglo XI Lantarón parece ser el área nuclear del territorio, Valpuesta la sede episcopal, Berbeia un lugar de asamblea, mientras que en Espejo y San Millán de Gabrinea se celebran asambleas judiciales. Por otro lado, desde principios del siglo XI Lantarón será reemplazado progresivamente por el castillo de Término (actual Santa Gadea del Cid). Pero este listado no recoge todos los centros de poder conocidos en el territorio de Lantarón y hay otros polos como Añana y Tobillas, que han desempeñado un papel clave en esta compleja trama política (Larrea Conde, 2007 2007; Plata Montero 2008). Además, esta diversidad refleja únicamente cuanto es conocido a través de los textos, por lo que un registro arqueológico más denso podría modificar ulteriormente este cuadro. Los datos arqueológicos disponibles muestran, por otro lado, que no hay correspondencia simple entre jerarquía y morfología, pero tampoco entre el grado de monumentalización de los distintos componentes del sistema y las funciones desempeñadas.

En definitiva, Lantarón cuenta con una estructura de poder distribuida y funcionalmente segregada, lo que es un rasgo común en otros espacios europeos carentes de 
SPAL 30.2

(2021)

\section{8-339}

ISSN: $1133-4525$ ISSN-e: 2255-3924 centros urbanos y/o formas de autoridad centralizadas, tal y como ocurre en los hundreds ingleses (Reynolds, 2019). Este alto grado de descentralización ha favorecido un alto nivel de experimentalidad política y de competitividad social a distintas escalas que ha permitido, por un lado, que los personajes titulados como los condes recurriesen a mecanismos de territorialización de carácter relacional y, por otro, que las élites intermedias encontrasen en estas autoridades canales de participación política que superasen los estrechos márgenes de los horizontes locales.

\section{DISCUSIÓN}

En esta sección se pretende discutir en términos más especulativos los registros materiales, con el fin de proponer algunas interpretaciones sobre la formación del condado de Lantarón a partir del análisis de las prácticas políticas y las formas de territorialización que se han dado en este territorio.

Los principales estudios sobre la evolución social han argumentado que la creación de ciudades constituye un estadio crítico en la emergencia de los estados y la creación de sistemas políticos dotados de un cierto nivel de complejidad (Johnson y Earle, 2000). Y aunque cada vez resulta más evidente que los estados secundarios postromanos se desarrollaron en buena parte de Europa en ausencia de ciudades (Brookes y Reynolds, 2019), los esfuerzos de muchos investigadores siguen centrándose en reconstruir la genealogía de los poderes urbanos y de los lugares centrales. Por otro lado, en el caso específico de Castilla hay un consenso generalizado entre los especialistas a la hora de considerar que tanto el corónimo como la propia articulación política del territorio responde a la existencia de una notable concentración de castillos en la zona en el contexto militarizado de la "Reconquista" (Martínez Díez, 2005). El principal problema de esta propuesta es que apenas conocemos un puñado de fortificaciones que puedan ser atribuidas con seguridad al período condal. Y aunque la ausencia de una gran densidad de castillos en Castilla puede ser un mero reflejo del estado de la investigación, ejemplos como el de Lantarón muestran que la realidad de las prácticas políticas en los territorios que conforman el "sistema castellano" desbordan la agencia de los poderes basados en fortificaciones y legitimados en términos militares.

Como punto de partida se tomará la secuencia cronológica que ha sido establecida a partir de los hallazgos arqueológicos y los registros paleoambientales relativos a la articulación de los paisajes altomedievales de Lantarón.

Se pueden atribuir a los siglos V-VI una serie de ocupaciones de altura que aún están poco caracterizadas en términos materiales y sociales. En otros territorios se ha sugerido que este patrón podría relacionarse con la emergencia de nuevos poderes o la readaptación de los ya existentes a escalas de acción más pequeñas tras el colapso del estado romano, que habrían generado dinámicas sociopolíticas más localizadas (Vigil-Escalera Guirado, 2015). Los escasos datos disponibles en Lantarón no permiten defender esta interpretación de forma rotunda, tanto por la escasa materialidad de estos hallazgos como por su breve duración. En todo caso, lo que sí se puede afirmar es que el fin del imperio no ha comportado una dramática simplificación sociopolítica ni la implantación de economías ganaderas nómadas que tradicionalmente han caracterizado el paradigma primitivista altomedieval. Más bien al contrario; los datos paleoambientales muestran precisamente una contracción de las actividades pecuarias durante los 
SPAL 30.2

(2021)

\section{8-339}

ISSN: $1133-4525$ ISSN-e: 2255-3924 siglos V-VII. Ello no quiere decir que la cría de animales y la explotación de pastos comunales no hayan constituido una actividad básica de la economía local, especialmente en los siglos VII-X, pero su relevancia no es un indicador de retroceso económico, sino más bien de una actividad integrada en determinadas lógicas productivas de explotación intensiva y diversificada.

Durante los siglos VII-VIII se produjo una profunda transformación de los paisajes, el poblamiento y las formas de sociabilidad de los habitantes de Lantarón. Este es aparentemente un período fecundo en la configuración de nuevas granjas y aldeas poco compactas, tal y como sugieren los casos de Bozoo o Tejuela, y de un incremento de la intensidad de las prácticas agrarias. La existencia de cementerios colectivos de larga duración creados en estos siglos constituye, a diferencia de lo que ocurre en el área nuclear alavesa, una expresión material del alto grado de cohesión interna de estas colectividades. Además, el uso de sepulcros y otros marcadores de distinción, como es el consumo puntual de cerámica pintada procedente del área castellana, constituyen un indicio del alto grado de competición social existente en la escala local.

De estas observaciones se puede inferir, por un lado, que en estos siglos había un alto nivel de compartimentación de las prácticas y los horizontes políticos, ya que los mecanismos de construcción de la memoria social y las estrategias de distinción iban dirigidas a una audiencia muy localizada. Por otro lado, se podría sugerir que las solidaridades y las relaciones horizontales cubrirían las expectativas económicas, sociales y políticas de estas sociedades locales. O dicho en otras palabras, este es un mundo dominado por micropolíticas articuladas en marcos de pequeña escala dotados de una notable estabilidad a largo plazo, de sociedades desiguales en pugna y en tensión interna.

A partir del siglo IX se observan cambios importantes. En primer lugar se documenta, tanto en términos materiales como textuales, la creación de monasterios e iglesias privadas realizadas con sofisticadas técnicas de cantería promovidas por élites supralocales y que, en algunos casos, cuentan con importantes recursos ganaderos. Teniendo en cuenta las tecnologías empleadas, es más que posible que en este proceso de petrificación del poder participasen cuadrillas itinerantes procedentes del área andalusí, que de esta manera introducen por vez primera en este sector del norte peninsular la retalla de sillares reutilizados y otros recursos antes desconocidos (fig. 11). Con todo, este grupo de poderosos precisa recurrir a elaborados mecanismos de apropiación de los recursos locales, como es el caso de la retórica de las presuras, para poder penetrar en estas realidades tan cohesionadas (Larrea Conde, 2007; Larrea Conde y Viader, 2005). Es decir, estas prácticas políticas gestadas desde fuera de las comunidades crean relaciones asimétricas mediante la participación de estos sujetos en las micropolíticas locales, con el fin de de construir e imponer relaciones de dominación. El recurso a los enterramientos privilegiados, como el hallado dentro de San Román de Tobillas, vuelve a ser una expresión de distinción dirigida a la audiencia local, que conoce y/o participa del ritual funerario. Como resultado de todo ello, a lo largo del siglo IX se habrían ido gestando toda una serie de "islas de autoridad" heterogéneas que pueden ser identificadas a través de esta arquitectura de alta calidad. Aunque posesores como Avito de Tobillas contasen con bienes distribuidos en varias localidades, la escala de acción de estos focos de poder debía de ser probablemente limitada y funcional, en un medio político caracterizado aún por prácticas políticas muy localizadas. Es decir, cuando más sólidas sean las sociedades locales frente a las 
SPAL 30.2 $(2021)$

\section{8-339}

ISSN: $1133-4525$ ISSN-e: 2255-3924

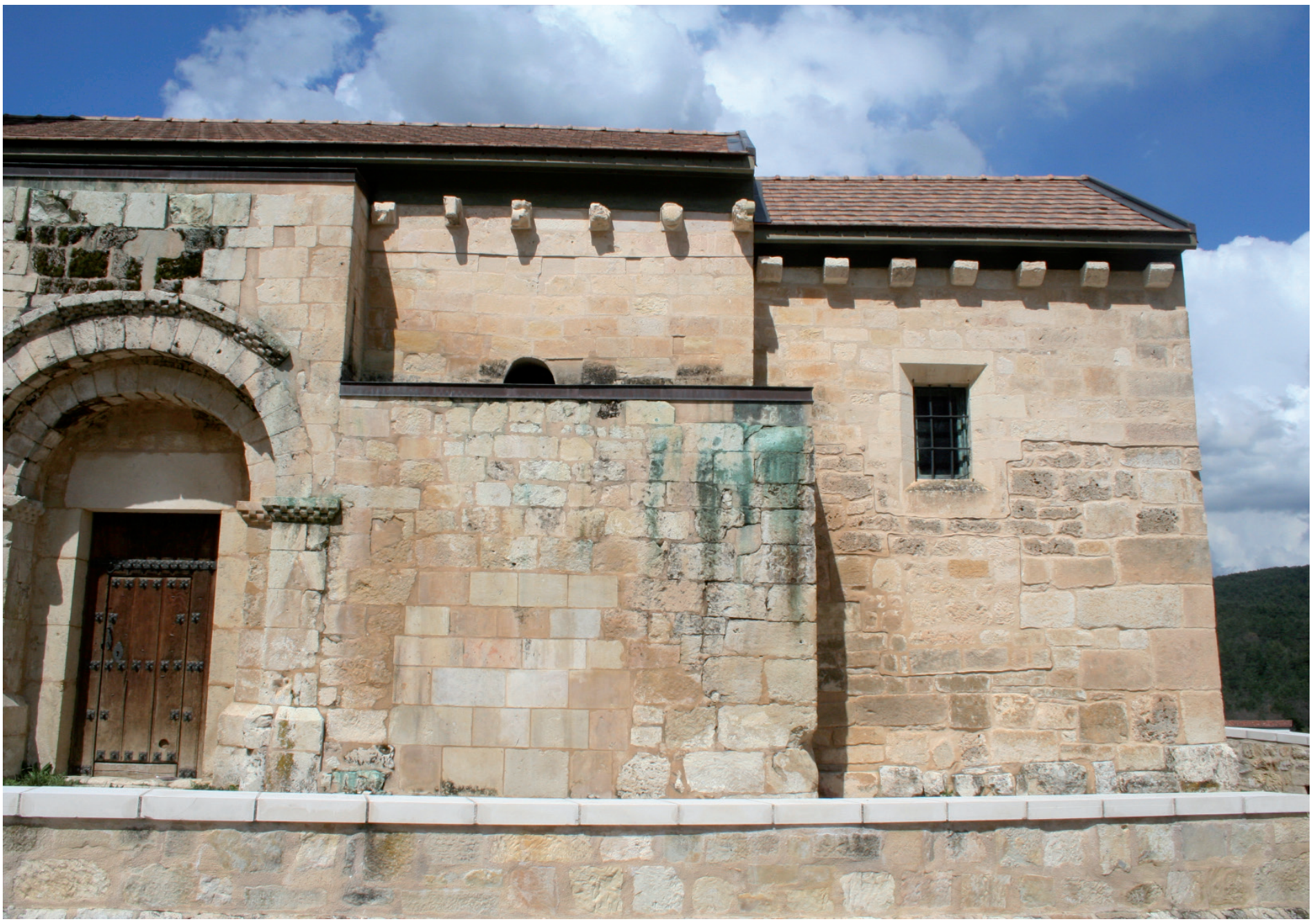

Figura 11. Cabecera de la iglesia de San Román de Tobillas (Valdegobia, Álava).

redes de patronazgo externo, tanto más se robustece el clientelismo interno en forma de elites aldeanas (Wickham, 2005, p. 438).

Desde mediados del siglo IX y durante el siglo $X$ tuvieron lugar una serie de cambios bastante profundos en el funcionamiento de Lantarón. A partir de entonces se detectan varios procesos convergentes. Por un lado, los registros paleoambientales del lago Arreo muestran que este es un período de intensa antropización del medio y del ulterior desarrollo de las prácticas agrarias. Por otro lado, se observan importantes transformaciones también en el seno de las aldeas. Así por ejemplo en lugares como San Miguele parece que cesa el empleo de los sarcófagos en el cementerio local. 0 al menos, aún no ha sido posible identificar ejemplares que se puedan fechar después de este momento. En segundo lugar, parece que se reduce el consumo de cerámica pintada en rojo en Lantarón, a la vez que empieza a ser más frecuente en los contextos de la llanada alavesa. En tercer lugar se documenta la existencia de un nuevo grupo de iglesias locales privadas realizadas en técnicas de albañilería, que podría estar denunciando un cambio de los promotores de este tipo de iniciativas. Por el contrario, en iglesias como San Román de Tobillas se recurre a una tecnología aún más elaborada (obra de cantería con sillares nuevos extraídos expresamente; espacios abovedados; selección de materiales, etc.), en ocasión de la implantación de nuevas formas de dominio subregional. La reconstrucción de la iglesia en el año 939, tal y como recuerda una lápida consagratoria, se debe atribuir a un miembro de la familia condal alavesa que aparece a cargo de uno de los principales focos de autoridad de Lantarón (Larrea Conde, 2007). Esto es, tras la unificación de los condados hacia el 930 se sigue recurriendo en la esfera local a prácticas de legitimación mediante la monumentalización del poder. Todos estos marcadores nos indican que las sociedades locales se ven desbordadas por nuevas prácticas políticas y mecanismos de participación en sistemas de mayor escala. 
SPAL 30.2

(2021)

\section{8-339}

ISSN: $1133-4525$

ISSN-e: 2255-3924

A su vez, la documentación textual empieza a iluminar el policentrismo y la diversidad de funciones que desempeñan los distintos componentes del territorio de Lantarón. Aunque se reconoce un área nuclear a orillas del Ebro, no parece contar con una materialidad reseñable respecto a otros centros de autoridad. Ni siquiera los castillos allí presentes, que probablemente se puedan retrotraer a este período, cuentan con estructuras monumentales, espacios habitacionales asociados o dimensiones de una cierta entidad. Es decir, Lantarón se presenta como un territorio jerarquizado pero basado en una serie de realidades heterárquicas que parecen funcionar en red (Ehrenreich et al., 1995). En cambio, en el área alavesa las jerarquías parecen ser más explícitas y lo mismo podría argumentarse para otros territorios castellanos, como es el caso de Tedeja, Peña Amaya, Lara o Castrojeriz. Por otro lado, las fuentes recogen, desde finales del siglo IX, la existencia de figuras de carácter condal en Lantarón y referencias sólidas acerca de la sede episcopal de Valpuesta. Nuevamente el contraste con otros territorios es evidente, hasta el punto de que sigue siendo difícil ubicar la sede episcopal alavesa antes del siglo XI y en otros casos se carece de referencias a sedes episcopales.

¿Cómo se produjo esta transformación tan radical de las prácticas políticas a distintas escalas en un plazo corto de tiempo? En el caso de los condados castellanos los especialistas han asumido que los personajes dotados de un título condal deberían contar con una sólida base patrimonial en los diferentes territorios en los que aparecen documentados (Escalona Monge y Reyes Téllez, 2011; Martín Viso, 2002). Documentos como la dotación del monasterio de Oña del año 1011 muestran la riqueza fundiaria de los condes castellanos a inicio del siglo Xl, pero también su carácter fragmentado y disperso. En cambio, la pesquisa de 1175 relativa a Lantarón muestra las limitaciones de los bienes fiscales en el área de Valdegobía. Además, carecemos de evidencias materiales o documentales relativas a grandes palatia en Lantarón, aunque en el área de Bachicabo o Bozoo se concentren varios de ellos. Es decir, más allá de que no tenemos certezas sobre las bases patrimoniales de los condes en la escala territorial en los siglos IX-X, esta no es una condición suficiente para explicar cómo se crean y articulan las nuevas prácticas políticas antes descritas.

Teniendo en cuenta el carácter heterárquico y difuso del sistema de poder que se ha dibujado, los condes han podido recurrir a formas de territorialización relacional, basadas en la negociación con los agentes intermedios que han ido emergiendo en las sociedades locales y que tenían el poder, pero no la autoridad, para conformar una estructura política de escala (ver Uphoff, 1989). Para ello los condes deberían suscitar consensos, generar convergencia de intereses y recurrir a una diversidad de mecanismos de legitimación. Entre estos últimos, algunos autores han subrayado la importancia que ha tenido el fuerte sentido de estatalidad en toda el área castellana durante la Alta Edad Media, respecto a otros sectores de la Europa Occidental (Davies, 2007, p. 24). Por otro lado J. Escalona ha mostrado recientemente, a través del estudio de la tradición documental, que en Lantarón los condes recurrieron de forma persistente a la legitimación de la monarquía, a pesar de ser un agente lejano e inactivo en la esfera local (Escalona Monge, 2016). Es decir, los condes sí contaban con la autoridad, pero su poder a escala territorial era débil. Ello explica por qué la traducción material de esta autoridad era menos monumental que las iglesias de las élites intermedias, y que fuese el capital simbólico más que la inversión económica la que caracterizase los focos de poder asociados al conde. Lantarón fue una plataforma útil para alcanzar otras ambiciones, pero no fue un fin en sí mismo. Paradójicamente el éxito de esta estrategia determinó el fin de Lantarón como microcondado, una vez que quedó subsumido en el 
SPAL 30.2

(2021)

\section{8-339}

ISSN: $1133-4525$ ISSN-e: 2255-3924 proyecto castellano. De hecho, la centralidad de Lantarón se vio suplantada en términos políticos a inicios del siglo XI por Término, a la vez que emergía de forma creciente Salinas de Añana como el núcleo económico en torno al que se concentra una diversidad de intereses, de tal forma que será la primera localidad alavesa que contaría con un fuero de concesión real (Plata Montero, 2008).

En cambio, y desde la esfera de las prácticas políticas locales, un sistema político de esta naturaleza favorecería la movilidad social y proporcionaría nuevos canales de participación política de las minorías dirigentes que, de esta manera, superaban los márgenes de las sólidas sociedades locales. El clientelismo y el patronazgo vendrían de esta manera a suplantar de forma creciente las relaciones horizontales que habian connotado las prácticas políticas anteriores (Santos Salazar, 2019). Es en este contexto en el que se crean las iglesias locales en el seno de las comunidades o por sus élites, recurriendo a mecanismos de representación que habían desarrollado los poderosos decenios antes. De hecho, cabe preguntarse hasta qué punto la complejización sociopolítica en la escala local y supralocal a lo largo del siglo IX es el antecedente necesario para que Lantarón pudiese convertirse en un foco de autoridad.

Aún no es posible establecer con detalle una genealogía de Lantarón o de otros condados castellanos. Analizando las formaciones estatales mediterráneas, S. Stoddart ha señalado que un cambio político profundo precisa de una transición rápida, de tal forma que el nuevo orden solo se aceptará si su implantación tiene lugar bajo ciertas condiciones de terapia de shock (Stoddart, 2000, p. 29). Además, estos puntos de inflexión tienen lugar en contextos de relaciones dinámicas y complejas entre una diversidad de agentes, de tal forma que son factores contingentes los que permiten generar cambios de calado (Stoddart, 2000, p. 30). Partiendo de esta premisa podría sugerirse que fueron factores coyunturales inducidos desde fuera (creación de un obispado, reconocimiento de determinados roles, etc.), en convergencia con las ambiciones de las élites de las sociedades locales en búsqueda de nuevos marcos de acción política, los que crearon las condiciones para que los aspirantes a obtener posiciones hegemónicas generasen formas de territorialización del poder de base relacional. Además, hay que enfatizar que alli donde han existido sedes episcopales (Lantarón y Álava), y por lo tanto una multiplicidad de agentes definiendo un modelo político heterárquico, el policentrismo es más acentuado que en otros sectores del "sistema castellano".

\section{CONCLUSIÓN}

La experiencia de Lantarón perduró únicamente pocas generaciones, ya que se documenta desde finales del siglo IX y se desvanece a lo largo del siglo X y XI. Fue una plataforma útil para una diversidad de agentes activos a distintas escalas en un contexto político y social muy específico. Cuando mutaron los marcos de acción política, el territorio de Lantarón no solamente dejó de bascular sobre el área nuclear homónima, sino que todo el sistema se diluyó en otro de mayor escala.

Se puede sugerir que, al lado de los dos modelos ideales propuestos por C. Wickham para definir los sistemas políticos altomedievales (estado de base fiscal o de política de tierras), Lantarón podría definir un tercer escenario. Reformulando los conceptos de Jessop (Jessop, 2017), se podría hablar de estado de base relacional en el que, aun en ausencia de un régimen de tasación o una sólida base patrimonial, la creación de consensos (en términos de equilibrio inestable entre rivalidad y cooperación), de canales 
SPAL 30.2

(2021)

\section{8-339}

ISSN: $1133-4525$ ISSN-e: 2255-3924 de participación política y de prácticas de negociación por autoridades legitimadas en un marco de estatalidad persistente, habría sido posible la construcción de territorialidades relacionales. Y aunque en ausencia total de bienes raíces no sería factible una política de esta naturaleza, no es la política de tierras la que articula las prácticas políticas de Lantarón, tal y como refleja la pesquisa de bienes fiscales del año 1175. Todo ello determinó la fortaleza y la debilidad de este territorio político. Y aunque es cierto que siguiendo a B. Jessop todos los estados precapitalistas son "estados relacionales", el ejemplo de Lantarón invita a explorar hasta qué punto la sinergia de intereses de distintos agentes y la legitimación de élites de carácter militar permiten construir un sistema político en equilibrio inestable como es un condado polinuclear. Se trata, en todo caso, de un modelo ideal en términos weberianos, en los que el eje principal de acción política no reposa únicamente en la persistencia de una determinada idea de estatalidad ni en la entidad de los bienes raíces, sino en una posición intermedia reforzada por la red de relaciones creadas en la escala local.

Otra conclusión a la que ha llegado este estudio es la coexistencia de una diversidad de culturas políticas y de fuertes diferencias subregionales en el sistema castellano altomedieval, lo que tiene importantes implicaciones para el desarrollo de nuevos proyectos futuros. Hace ya medio siglo que J. A. García de Cortázar argumentó la existencia de "dos Álavas" altomedievales, constatando la existencia de distintas sociedades a ambos lados del río Bayas, lo que se interpretó en términos de mayor jerarquización y complejidad en el área de Lantarón respecto a Álava nuclear (García de Cortázar, 2005). Esta fecunda propuesta ha sido posteriormente desarrollada en varios estudios arqueológicos, añadiendo matices e incluso lecturas contradictorias. Si la distribución de las iglesias altomedievales venía a confirmar las intuiciones de García de Cortázar, el análisis de los patrones de circulación y consumo cerámico apuntaba en una dirección opuesta, mostrando la existencia de jerarquías más explícitas en la llanada alavesa respecto a los valles occidentales. Más recientemente los estudios de carácter filológico han aportado otro punto de vista, subrayando la diferencia cultural existente entre ambos espacios, pero manteniendo siempre como referencia el río Bayas (Ramos Remedios, 2019).

El estudio de las prácticas políticas seguido en este ensayo propone un cuadro algo más articulado. La comparación entre Lantarón y Álava nuclear ha mostrado una diversidad de mecanismos de construcción de comunidades políticas, más cohesionadas y localizadas en el primer caso, más anidadas y abiertas en el segundo. Asimismo, los registros materiales apuntalan la idea de que los mecanismos de distinción, las formas de conectividad y de construcción de vínculos de carácter clientelar seguidos por las élites intermedias han seguido distintos canales en ambos territorios. ¿Se pueden traducir estas diferencias en términos de gradación de la complejidad sociopolítica? No necesariamente. Ambos territorios pueden ser definidos en términos de polinuclearidad competitiva basada en formas de división funcional de las sedes de poder, que responden a una lógica heterárquica jerarquizada. Pero las culturas políticas eran diferentes. Por otro lado, sí se abre el angular al análisis de la materialidad de las prácticas políticas de otros territorios próximos, como es el Ebro en el tramo riojano, el área de Tedeja o Pancorbo, se intuyen otras culturas políticas que presentan diferencias más o menos acentuadas respecto a Lantarón y/o Álava.

Por último, habría que concluir que el carácter policéntrico y difuso de la geografía política de los condados castellanos determina que las estrategias de investigación futuras no puedan ceñirse al estudio de los espacios centrales, cuando estos existen. Sería preciso desarrollar proyectos a escala territorial y de larga duración que consideren 
SPAL 30.2

$(2021)$

308-339

ISSN: $1133-4525$

ISSN-e: 2255-3924 una diversidad de casos de estudio, con el fin de identificar en términos relacionales y comparativos la complejidad de los sistemas políticos altomedievales.

\section{Agradecimientos}

A lo largo de los años se han ido contrayendo deudas de agradecimiento con numerosas personas e instituciones, entre las que hay que señalar al personal de la Diputación Foral de Álava, las instituciones locales, así como los vecinos de los municipios de Valdegobía y Lantarón, que han proporcionado numerosas informaciones. En particular hay que agradecer su apoyo a este proyecto a Javier Fernández Bordegarai, Antxoka Martínez Velasco, Juan Carlos Abascal Ruiz de Aguirre, Anton Arrieta, Leandro Sánchez Zufiaurre, Ángel Palomino, Igor Santos Salazar, Stuart Brookes, Andrew Reynolds, Pedro Lobo, Lorena Elorza, Carlos Tejerizo, Francesca Grassi, Maite Iris García y Alfonso Vigil-Escalera. Asimismo las evaluaciones externas han contribuido a mejorar notablemente el original.

Este trabajo ha sido realizado en el marco de los Proyectos "Agencia campesina y complejidad sociopolítica en el noroeste de la Península Ibérica en época medieval" (AEI/FEDER UE HUM2016-76094-C4-2-R) y "Arqueología de las sociedades locales en el sur de Europa: identidades, colectivos y territorialidades" (PID2020-112506GB-C41), del Grupo de Investigación en Patrimonio y Paisajes Culturales (Gobierno Vasco, IT936-16) y del Grupo de Estudios Rurales (Unidad Asociada UPV/EHU-CSIC).

\section{BIBLIOGRAFÍA}

Agorreta, J. A., Llanos, A., Apellaniz, J. M., Farina, J. (1975) "Castro de Berbeia (Barrio, Álava), Memoria de excavaciones. Campaña de 1972", Estudios de Arqueología Alavesa, VIII, pp. 221-92.

Alonso Martínez, I. (2014) Lantarón: fortaleza y condado. Un microcosmos altomedieval. Zamora: Monte Casino.

Álvarez Borge, I. (1987) “El proceso de transformación de las comunidades de aldea: una aproximación al estudio de la formación del feudalismo en Castilla (siglos X y XI)", Studia historica. Historia medieval, 5, pp. 145-60.

Aratikos. (2015) Sondeos arqueológicos en el entorno de la necrópolis de Santa María de Tejuela, Villanueva Soportilla (Bozoó, Burgos). Burgos, Informe técnico inédito depositado en el archivo de la Delegación de Cultura la Junta de Castilla y León.

Azkarate Garai-Olaun, A., Solaun Bustinza, J. L. (2016) “La cerámica altomedieval en el País Vasco (siglos V-X d.C): producciones, modelos productivos y patrones de consumo", en Vigil-Escalera Guirado, A., Quirós Castillo, J. A. (eds.) La cerámica de la Alta Edad Media en el cuadrante noroeste de la Península Ibérica (siglos V-X): sistemas de producción, mecanismos de distribución y patrones de consumo, Bilbao: Universidad del País Vasco, pp. 193-228.

Azkarate Garai-Olaun, A. (1995) “Aportaciones al debate sobre la arquitectura prerrománica peninsular: la iglesia de San Román de Tobillas (Álava)" Archivo Español de Arqueología, 68, pp. 188-214. https://doi.org/10.3989/aespa.1995.v68.422.

Becerro de Bengoa, R. (1918) Descripciones de Álava. Vitoria-Gasteiz: Real Ateneo.

Bianchi, G., Lazzari, T., La Rocca, C. (2018) Spazio pubblico e spazio privato Tra storia e archeologia (secoli VI-XI). Turhnout: Brepols.

Brookes, S., Reynolds, A. (2019) "Territoriality and Social Stratification: The Relationship between Neighbourhood and Polity in Anglo-Saxon England", en Escalona, J., Vésteinsson, O., Brookes, S. (eds.) Polity and Neighborhood in Early Medieval Europe. Turnhout: Brepols, pp. 267-304. 
SPAL 30.2

$(2021)$

308-339

ISSN: $1133-4525$ ISSN-e: 2255-3924
Campillo Cueva, J. (1996) "Las necrópolis medievales cristianas en la comarca mirandesa (Burgos)." Kobie Serie Paleoantropologia, XXIII, pp. 111-139.

Caro Baroja, J. (1983) Historia general del País Vasco. San Sebastián: La Gran Enciclopedia Vasca. Carvajal Castro, Á. (2017) Bajo la máscara del "Regnum": La monarquía asturleonesa en León (854-1037). Madrid: CSIC.

Carvajal Castro, Á., Narbarte Hernández, J. (2019) "Royal power and proprietary churches in the eleventh-century Kingdom of Pamplona", Journal of Medieval Iberian Studies, 11, pp. 115-34. https://doi.org/10.1080/17546559.2019.1566760.

Castellanos, S., Martín Viso, I. (2005) "The local articulation of central power in the north of the Iberian Peninsula (500-1000)", Early Medieval Europe, 13.1, pp. 1-42. https://doi. org/10.1111/j.1468-0254.2005.00147.x.

Davies, R. (2003) “The Medieval State: The Tyranny of the Concept?", Journal of Historical Sociology, 16.2, pp. 280-300. https://doi.org/10.1111/1467-6443.00206.

Davies, W. (2007) Acts of giving: individual, community, and church in tenth-century Christian Spain. Oxford: Oxford University Press.

Davies, W. (2016) Windows on justice in Northern Iberia, 800-1000. Abindgon: Ashgate.

Díaz Martínez, P., Martín Viso, I. (eds) (2011) Between taxation and rent: fiscal problems from late Antiquity to early Middle Ages. Bari: Edipuglia.

Ehrenreich, R. M., Crumley, C. L., Levy, J. E., Crumley, C. L. (1995) Heterarchy and the Analysis of complex Societies. Arlington: Society of American Archaeology.

Escalona Monge, J. (2016) "In the name of a distant king: representing royal authority in the county of Castile, c.900-1038", Early Medieval Europe, 24, pp. 74-102. https://doi.org/10.1111/ emed.12134.

Escalona Monge, J., Reyes Téllez, F. (2011) "Scale Change on the Border: The County of Castile in the Tenth Century", en Escalona Monge, J. y Reynolds, A. Scale and scale change in the Early Middle Ages: exploring landscape, local society, and the world beyond. Turnhout: Brepols, pp. 153-86.

Escalona Monge, J., Reynolds, A. (2011) Scale and scale change in the early middle ages: exploring landscape, local society and the world beyond. Turnhout: Brepols.

Escalona Monge, J., Vésteinsson, O., Brookes, S. (eds.) (2019) Polity and neighborhood in early medieval Europe. Turnhout: Brepols.

Estepa Díez, C. (2009). "La Castilla primitiva (750-931): condes, territorios y villas", en Fernández Conde, F. J. y García de Castro Valdés, C. (eds) Symposium Internacional Poder y Simbología en Europa, siglos VIII-X. Gijón: Trea, pp. 261-78.

Fernández Conde, F. J., Fernández Fernández, J. (2010) “El territorio de Buanga (Asturias): Génesis y formación de un alfoz altomedieval", Territorio, Sociedad y Poder, 5, pp. 35-67.

Fernández, D. (2017) Aristocrats and Statehood in Western Iberia, 300-600 C.E. Philadelphia: University of Pennsylvania Press.

Fernández de Palomares, V. (1979) “Lantarón”, Boletín de la Institución Sancho El Sabio, 23, pp. 35-60.

Fernández Flórez, J. A., Serna Serna, S. (2017) El Becerro Gótico de Cardeña. El primer gran cartulario hispánico (1086). Madrid: Real Academia de la Lengua Española.

Flannery, K., Marcus, J. (2012) The Creation of Inequality: How Our Prehistoric Ancestors Set the Stage for Monarchy, Slavery and Empire. Harvard: Harvard University Press.

Flórez, E. (1771) España Sagrada tomo XXVI. Contiene el estado antiguo de las iglesias de Auca, de Valpuesta y de Burgos. Madrid: Pedro María.

Fuente, M. J. (2008) “El estado ha muerto ¡Viva el Estado! Debates historiográficos sobre el estado en la Edad Media", Revista de Historiografía, 9.2, pp. 33-49.

García Camino, I. (2002) Arqueología y poblamiento medieval en Bizkaia (siglos VI-XII): la configuración de la sociedad feudal. Bilbao: Diputación Foral de Bizkaia.

García Collado, M. I. (2013) “El enterramiento privilegiado de San Román de Tobillas (Tobillas, Álava)”, en Compañy, G., Fonte, J., Gómez-Arribas, B., Moragón Martínez, L. y Señorán Martín, J. 
SPAL 30.2

$(2021)$

308-339

ISSN: $1133-4525$ ISSN-e: 2255-3924
M. (eds.) Arqueología para el siglo XXI: actas de las V Jornadas de Jóvenes en Investigación Arqueológica. Madrid: JAS Arqueología, pp. 131-6.

García de Cortázar, J. Á. (2005) Investigaciones sobre historia medieval del País Vasco (19652005): 20 artículos y una entrevista. Bilbao: Universidad del País Vasco.

García de Cortázar, J. Á. (2018) La construcción de la Diócesis de Calahorra en los siglos X a XIII: la iglesia en la organización social del espacio. Logroño: Instituto de Estudios Riojanos.

Gil Zubillaga, L., Sáenz de Urturi Rodríguez, F. (2001) San Miguele. La necrópolis tardorromana, tardoantigua y altomedieval de San Miguele (Molinilla, Álava). Vitoria-Gasteiz: Diputación Foral de Álava.

Godoy, A. (2019) “Riqueza, circulación de bienes y élites rurales en León en los siglos XyXI”, Sociedades Precapitalistas: Revista de Historia Social, 9: e033. https://doi.org/10.24215/22505121e033.

González Salazar, J. A. (1989) Toponimia menor de Añana. Cuadernos de toponimia, 6. Vitoria-Gasteiz: Diputación Foral de Álava.

Grassi, F., Fornacelli, C. (2018). "New archaeometrical data on red-painted pottery: case study of northern Iberia", en Grassi, F. y Quirós Castillo, J. A. (eds.) Arqueometría de los materiales cerámicos en el norte de la Península Ibérica: métodos y estrategias para el futuro. Bilbao: Universidad del País Vasco, pp. 133-62.

Gutiérrez González, J. A. (1995) Fortificaciones y feudalismo en el origen y formación del Reino Leonés (siglos IX-XIII). Valladolid: Universidad de Valladolid.

Gutiérrez Lloret, S. (2017) "Early al-Andalus: an Archaeological Approach to the Process of Islamization in the Iberian Peninsula (7th to 10th centuries)", en Gelichi, S. y Hodges, R. (eds), New directions in Early medieval European archaeology: Spain and Italy compared: essays for Riccardo Francovich. Turnhout: Brepols, pp. 43-86.

Inmaculada, E. (1943) Historia del santuario de Nuestra Señora de Angosto y del valle de Gobea de la M N y M L provincia de Álava. San Sebastián: Fides.

Jessop, B. (2007) State power: a strategic-relational approach. Cambridge: Polity.

Jessop, B. (2016) The state: past, present, future. Malden: Polity Press.

Jessop, B. (2017) El Estado. Pasado, Presente, Futuro. Madrid: La Catarata.

Johnson, A. W., Earle, T. (2000) The Evolution of Human Societies: From Foraging Group to Agrarian State. Stanford: Stanford University Press.

Landazuri, J. J. (1798) Los compendios históricos de la ciudad y las villas de la M. N. y M. leal provincia de Álava recopilados de los documentos de sus archivos y de otros del reino. Pamplona: Imprenta de Miguel de Cosculluela.

Larrea Conde, J. J. (2007) “Construir iglesias, construir territorio: las dos fases altomedievales de San Román de Tobillas (Álava)", en López Quiroga, J., Martínez Tejera, A. M. y Morín de Pablos, J. (eds) Monasteria et territoria. Elites, edilicia y territorio en el Mediterraneo medieval (siglos V-XI), Oxford: Archaeopress, pp. 321-336.

Larrea Conde, J. J. (2009) "Construir un reino en la periferia de Al-Ándalus: Pamplona y el Pirineo occidental en los siglos VIII y IX", en Fernández Conde, F. J. y García de Castro Valdés, C. (eds.) Symposium Internacional Poder y Simbología en Europa, siglos VIII-X. Gijón: Trea, pp. 279-308.

Larrea Conde, J. J., Viader, R. (2005) “Aprisions et presuras au début du IXe siècle: pour une étude des formes d'appropriation du territoire dans la Tarraconaise du haut Moyen Âge", en Sénac, P. (ed.) De la Tarraconaise à la Marche supérieure d'Al-Andalus (IVe-XIe siècle). Toulouse: Université du Toulouse, pp. 167-210.

Lecanda Esteban, J. A. (2015) Estudio arqueológico del Desfiladero de La Horadada: La transición entre la tardorromanidad y la Alta Edad Media (ss.V-X d.n.e.). Tesis doctoral, Burgos: Universidad de Burgos. Doi: 10.36443/10259/4641.

Ledesma Rubio, M. L. (1989) Cartulario de San Millán de la Cogolla (1076-1200). Zaragoza: Universidad de Zaragoza.

Leorza Alvarez de Arcaya, R. (2011) "Iglesia de San Esteban. Exterior", Arkeoikuska, 11, pp. 73-75. Loré, V., Bougard, F. (eds.) (2019) Biens publics, biens du roi, Les bases économiques des pouvoirs royaux dans le haut Moyen Âge. Turnhout: Brepols. 


\section{SPAL 30.2 $(2021)$}

\section{8-339}

ISSN: $1133-4525$ ISSN-e: 2255-3924
Marcos Martínez, J., Mantecón Callejo, L. (2009) "El castillo de monte Subiedes (Camaleño, Liébana, Cantabria): Control del territorio lebaniego en la Alta Edad Media", Territorio, Sociedad y Poder, 4, pp. 95-130.

Marcus, J. (2008) "The Archaeological Evidence for Social Evolution", Annual Review of Anthropology, 37.1, pp. 251-66. https://doi.org/10.1146/annurev.anthro.37.081407.085246.

Martín Viso, I. (2002) "Poder político y estructura social en la Castilla altomedieval: el condado de Lantarón (siglos VIII-XI)", en De la Iglesia Duarte, J. I. y Martín Rodríguez, J. L. (eds) Los espacios de poder en la España medieval. Logroño: Instituto de Estudios Riojanos, pp. 533-552.

Martín Viso, I. (2016) "Colapso político y sociedades locales: El noroeste de la Península Ibérica (siglos VIII-IX)", Reti Medievali Rivista, 17.2, pp. 335-369.

Martín Viso, I. (2017) "Integración política y regeneración: el sur del Duero en el Reino Asturleonés", Edad Media: revista de historia, 18, pp. 207-239. https://doi.org/10.24197/em.18.2017.207-239.

Martín Viso, I. (2019). "Las propiedades regias y la formación del Reino Asturleones (850-950)", en Bougard, F. y Loré, V. (eds.) Biens publics, biens du roi. Les bases économiques des pouvoirs royaux dans le haut Moyen Âge. Turhnout: Brepols, pp. 179-212.

Martín-Viso, I. (2020) "Commons and the construction of power in the early Middle Ages: tenth-century León and Castile", Journal of Medieval History, 46.4, pp. 373-395. https://doi.org/1 $0.1080 / 03044181.2020 .1784777$.

Martínez Díez, G. (1981) Libro Becerro de las Behetrías. Estudio y texto crítico. León: Centro de Estudios San Isidoro.

Martínez Díez, G. (2005) El condado de Castilla, 711-1038: la historia frente a la leyenda. Valladolid: Junta de Castilla y León.

Milanovic, B. (2016) Global Inequality: A New Approach for the Age of Globalization. Harvard: Harvard University Press.

Muñiz López, I., Gutiérrez González, J. A. (2004) "Reflexiones sobre los centros de poder en el "Asturorum Regnum": de las crónicas al paisaje", en AA. VV. Sulcum sevit: estudios en homenaje a Eloy Benito Ruano. Oviedo: Universidad de Oviedo, pp. 333-372.

$\varnothing$ degaard, M. (2013) "State Formation, Administrative Areas, and Thing Sites in the Borgarthing Law Province, Southeast Norway", Journal of the North Atlantic, Special Volume 5, pp. 42-63.

Ortiz de Urbina, C. (1996) El desarrollo de la arqueología en Álava: condicionantes y conquistas (siglos XVIII y XIX). Vitoria-Gasteiz: Diputación Foral de Álava.

Peña Bocos, E. (1995) La atribución social del espacio en la Castilla altomedieval: una nueva aproximación al feudalismo peninsular. Santander: Universidad de Cantabria.

Peña Bocos, E., Díez Herrera, C., García de Cortázar, J. Á. (1998) “Nombres y apellidos en Lantarón (siglos IX-XII): ¿Vinculaciones lingüísticas, étnicas o culturales?", en AA. VV. Scripta: estudios en homenaje a Elida García García. Oviedo: Universidad de Oviedo, pp. 207-40.

Pérez de Urbel, J. (1945) Historia del condado de Castilla. Madrid: CSIC.

Plata Montero, A. (2008) Génesis de una villa medieval. Arqueología, paisaje y arquitectura del valle salado de Añana (Álava). Vitoria-Gasteiz: Gobierno Vasco.

Pohl, W., Wieser, V. (2009) Der frühmittelalterliche Staat: europäische Perspektiven. Viena: Verlag der österreichischen Akademie der Wissenschaften.

Portilla Vitoria, M. J. (1984) “Arte Románico. Raíces y evolución”, en Jiménez, J. (ed) Álava en sus manos. Caja Vital: Vitoria-Gasteiz, pp. 41-72.

Price, D., Feinman, G. (2012) Pathways to Power: New Perspectives on the Emergence of Social Inequality. Nueva York: Springer.

Quark (2017) Memoria Técnica del Control arqueológico efectuado en el marco del "Proyecto de desarrollo constructivo de la infraestructura hidráulica de la red en alta de la zona regable de Valles alaveses, Zona 4. Red de distribución. Memoria inédita disponible en el Museo BIBAT. Vitoria-Gasteiz.

Quintana López, J. (2017) El Castro de Peña Amaya (Amaya, Burgos): del Nacimiento de Cantabria al de Castilla. Santander: Instituto de Prehistoria y Arqueología Sautuola.

Quirós Castillo, J. A. (2012) Informe del proyecto arqueológico de Lantarón. Vitoria-Gasteiz, Informe técnico inédito disponible en el Museo BIBAT. Vitoria-Gasteiz. 


\section{SPAL 30.2 $(2021)$}

\section{8-339}

ISSN: $1133-4525$ ISSN-e: 2255-3924
Quirós Castillo, J. A. (2020a) "Pertenecer y diferenciarse. Iglesias "locales" y agencia campesina en el noroeste de la Península Ibérica”, Studia Historica, Historia Medieval, 38.1, pp. 117-152. https://doi.org/10.14201/shhme2020382117152.

Quirós Castillo, J. A. (2020b) Valdegobía en el inicio de su historia. Vitoria-Gasteiz: Diputación Foral de Álava.

Quirós Castillo, J. A. (2020c) "Village Formation, Social Memories and the Archaeology of Rural Communities in North-Western Iberia", en Quirós Castillo, J. A. (ed.) Social Inequality in Early Medieval Europe: Local Societies and Beyond. Turnhout: Brepols, pp. 301-329.

Quirós Castillo, J. A., Santos Salazar, I. (2012) "I villaggi medievali nell'Alto Ebro alla luce delle fonti scritte e dell'archeologia. L'emergere dei leader dei villaggi e l'articolazione dei poteri territoriali nel X secolo", en Galetti, P. (ed) Paesaggi, comunità, villaggi medievali. Spoleto: Centro di Studi sull'Altomedioevo, pp. 257-282.

Quirós Castillo, J. A., Santos Salazar, I. (2015) "Territorios sin ciudades y complejidad social. El Cantábrico oriental en la Alta Edad Media”, en Sabaté Curull, F. (ed.) La ciutat Medieval i Arqueologia. VI Curs Internacional d'Arqueologia Medieval. Lérida: Paidós, pp. 139-174.

Ramos Remedios, E. (2019) "Sobre la lengua romance patrimonial en Álava (siglos V al XI): la aportación de la arqueología", Anuario de Estudios Medievales, 47.1, pp. 303-334. DOI: https://doi.org/10.3989/aem.2017.47.1.11.

Reynolds, A. (2018) "Lineage, genealogy and landscape: a high-resolution archaeological model for the emergence of supra-local society from early medieval England", World Archaeology, 50.1, pp. 121-136. https://doi.org/10.1080/00438243.2018.1500303-

Reynolds, A. (2019) "Spatial Configurations of Power in Anglo-Saxon England: Sidelights on the Relationships between Boroughs, Royal Vills and Hundreds", en Carroll, J., Reynolds, A. y Yorke, B. (eds.) Power and Place in Europa in the Early Middle Ages. Oxford: Oxford University Press, pp. 436-455.

Reynolds, S. (1997) "The Historiography of the Medieval State", en Bentley, M. (ed.) Companion to Historiography. Nueva York: Springer, pp. 109-129.

Rodríguez de Lama, I. (1976) Colección diplomática medieval de La Rioja 2. Documentos: 9231168. Logroño: Instituto Estudios Riojanos.

Routledge, B. (2014) Archaeology and State Theory: Subjects and Objects of Power. Londres: Bloomsbury.

Ruiz Asensio, J. M., Ruiz Albi, I., Herrero Jiménez, M. (2010) Los Becerros Gótico y Galicano de Valpuesta. Madrid: Real Academia de la Lengua Española.

Ruiz de Loizaga, S. (1979) "Las ermitas del Arciprestazgo de Valdegovía (Alava) en el año 1850", Boletín de la Real Sociedad Vascongada de Amigos del País, 35, pp. 294-301.

Ruiz de Loizaga, S. (1982) Monasterios altomedievales del Occidente de Alava. Valdegovía. Como nacen los pueblos. Vitoria-Gasteiz: Diputación Foral de Álava.

Sáenz de Urturi Rodríguez, F. (2011) “Memoria de las intervenciones arqueológicas realizadas en Astúlez: sondeos estratigráficos en los yacimientos de El Castillo y Santa Coloma (Astúlez, Valdegobía, Álava)", Estudios de Arqueología Alavesa, 27, pp. 229-358.

Sagredo, I. (2007) Navarra. Castillos que defendieron el Reino. Tomo III: La Navarra occidental, la frontera del mar. Álava, Bizkaia, el Duranguesado, Guipuzkoa. Pamplona: Pamiela argitaletxea.

Sánchez Zufiaurre, L. (2007) Técnicas constructivas medievales: Nuevos documentos arqueológicos para el estudio de la Alta Edad Media en Álava. Vitoria-Gasteiz: Gobierno Vasco.

Santos Salazar, I. (2013) "Los privilegios de Berbeia y Barrio: elites, memoria y poder en Lantarón durante el siglo X", Studia historica. Historia medieval, 31, pp. 51-81. Doi: 10.14201

Santos Salazar, I. (2019) "Competition in the frontiers of the Asturian Kingdom: The Comites of Castile, Lantarón and Álava (860-940)", en Le Jan, R., Bührer-Thierry, G. y Gasparri, S. (eds) Coopétition. Rivaliser, coopérer dans les sociétés du haut Moyen Âge (500-1100). Turhnout: Brepols, pp. 231-251.

Scheidel, W. (2017) The Great Leveler: Violence and the History of Inequality from the Stone Age to the Twenty-First Century. Princeton: Princeton University Press. 


\section{SPAL 30.2 $(2021)$}

\section{8-339}

ISSN: $1133-4525$ ISSN-e: 2255-3924
Solaun Bustinza, J. L. (2005) Erdi aroko zeramika Euskal Herrian (VIII.-XIII. mendeak): ekoizpenaren sistematizazioa, bilakaera eta banaketa $=$ La cerámica medieval en el País Vasco (siglos VIII-XIII): sistematización, evolución y distribución de la producción. Vitoria-Gasteiz: Gobierno Vasco.

Solaun Bustinza, J. L. (2018) "Conjunto monumental de Portilla", Arkeoikuska: Investigación arqueológica, 2018: pp. 204-210.

Stoddart, S. (2000) "Boundaries of the State in Time and Space: Transitions and Tipping Points", Social Evolution and History, 9.2, pp. 28-52.

Terrenato, N., Haggis, D. C. (eds.) (2011) State formation in Italy and Greece: questioning the neoevolutionist paradigm. Oxford: Oxbow.

Trueba, A. (1871) "Los sepulcros de Cantabria (conclusión V)", La Ilustración Española y Americana, XV, 25, pp. 419-422.

Uphoff, N. (1989) "Distinguishing Power, Authority \& Legitimacy: Taking Max Weber at His Word by Using Resources-Exchange Analysis", Polity, 22 (2), pp. 295-322. DOI: https://doi. org/10.2307/3234836.

Urcelay Gaona, H. (2019) Los Sarmiento, Condes de Salinas: orígenes y elevación de una nueva clase señorial, siglos XII-XVI. Bilbao: Universidad del País Vasco.

Velasco y Fernández de Cuesta, L. (1879) Los euskaros en Álava, Guipúzcoa y Vizcaya. Sus orígenes, Historia, lengua, leyes, costumbres y tradiciones. Barcelona: Oliveres.

Vigil-Escalera Guirado, A. (2015) Los primeros paisajes altomedievales en el interior de Hispania: registros campesinos del siglo quinto d.C. Bilbao: Universidad del País Vasco.

Wickham, C. (2005) Framing the early Middle Ages: Europe and the Mediterranean, 400-800. Oxford: Oxford University Press. 